\title{
International Journal of Industrial Engineering Computations
}

\section{Integrated modeling of the peer-to-peer markets in the energy industry}

\author{
Gonzalo E. Alvarez ${ }^{a^{*}}$
}

${ }^{a} I N G A R / C O N I C E T-U T N$, Instituto de Desarrollo y Diseño. Avellaneda 3657, S3000, Santa Fe, Argentina

\section{H R O N I C L E \\ A B S T R A C T}

\section{Article history:}

Received May 82021

Received in Revised Format

July 122021

Accepted July 142021

Available online

July, 142021

Keywords:

Optimization

Energy system integration

P2P electricity trading

Traditional systems

Decentralized systems

Electricity Industry

\begin{abstract}
Over time, the number of smart grids installed worldwide is gradually increasing. However, the major portion of the required electricity is still being produced by traditional large-scale and centralized power systems. The main requirement, then, is to study and develop mathematical methods that attend the integration between the two systems previously announced. In this paper, a novel model that addresses this issue is presented. The model minimizes the total operating cost of the large-scale system considering the participation of the smart grid as a dynamic entity, entailing a close relationship between both systems. This approach distinguishes the novel proposal from others that solve similar situations by taking into account the two systems in isolation. Besides, the models that represent the most common organizational structures of the smart grids are also presented in this paper. They are needed to develop the integrated model. Many similar problems in the literature are solved by implementing decomposition techniques, which might obtain a local optimum different from the global one. By contrast, problems with this proposal are solved by using mixed-integer linear programming models that ensure the reaching of a global optimum. The real test case is the integrated Argentine large-scale system and the Armstrong smart grid. Results indicate that the novel model can reach solutions that are 5\% lower in comparison with the traditional techniques of considering in isolation. Efficient CPU times enable the possibility of promptly obtaining solutions if there is any change in the parameters. In addition, other benefits, apart from the economical reductions, are also achieved. Operating information closer to the reality of both systems is obtained because it considers the effects of the smart grid in large-scale system solving.
\end{abstract}

(C) 2022 by the authors; licensee Growing Science, Canada

\section{Nomenclature}

\section{Acronyms}

$P 2 P$
$B S L$
$C M$
$I S O$
$D C$
INT
Indexes

$i / j$

$l$

$c / \mathrm{d}$

$g u$

bu

* Corresponding author

E-mail: galvarez@santafe-conicet.gov.ar (G. E. Alvarez)

2022 Growing Science Ltd. doi: $10.5267 /$ j.ijiec.2021.7.002
Peer-to-peer

Block System Linear (model)

Community manager

Independent System Operator

Distribution company

Integrated

Peer index

Transmission line index

Community index

Unit block index

Bus index 
Constants

$$
\begin{aligned}
& \quad c g_{i} \\
& p r_{i . j}^{s} / p r_{i . j}^{b} \\
& p r_{i . j . t}^{g} \\
& p_{l . j}^{l} \\
& x_{i}^{\text {max }} / x_{i}^{\text {min }} \\
& d k t_{i} \\
& p r_{i . j}^{b} / p r_{i . j}^{s} \\
& \operatorname{prc}_{i . c}^{b} / \operatorname{prc}_{i . c}^{s} \\
& \operatorname{pr}_{i . c}^{g} \\
& \operatorname{pr}_{c . d}^{t} \\
& \delta^{g} / \delta^{n g} / \delta^{h} / \delta^{n} / \delta^{w} / \delta^{p v}
\end{aligned}
$$

\section{Variables}

$$
\begin{aligned}
& S C \\
& x_{i . j . t} / y_{i . j . t} \\
& \rho_{\text {i.ct. }} / \sigma_{\text {i.c.t }} \\
& \delta_{c . t} / \gamma_{c . t} \\
& g_{i . t} \\
& p_{-} n e t_{i . t} \\
& t_{-} x_{i . t} / t_{-} y_{i . t} \\
& u_{-} s_{\text {sell }} \text { i.t } / u_{-} b u y_{i . t} \\
& \mu_{\text {c.d.t }}^{\text {imp }} / \mu_{\text {c.d.t }}^{\text {exp }} \\
& \operatorname{distr}_{\text {comp }}{ }_{c . t} / \text { distr }_{\text {comp }}{ }_{c . t}^{s} \\
& p_{g u . b u}^{g} / p_{g u . b u}^{n g} / p_{g u . b u}^{h} / \\
& p_{g u . b u}^{n} / p_{g u . b u}^{w} / p_{g u . b u}^{p v}
\end{aligned}
$$

Cost for generating electricity (USD/MWh)

Selling/purchase price (USD/MWh)

Price for using transmission lines (USD/MW)

Line capacity (MW)

Trade power limits (MW)

Power consumption (MW)

Hourly purchase/selling price between peers (USD/MWh)

Hourly purchase/selling price between peer and community manager (USD/MWh)

Cost for using grid that peer pays to community manager (USD/MWh)

Trade cost between communities (USD/MWh)

Coefficients of fuel cost function for gas/non gas/hydro/nuclear/wind/PV units (USD/MWh)

Social cost (USD)

Traded electricity for purchasing/selling between peers (MW)

Traded power for purchasing/selling between peers and community manager (MW)

Electricity amount that the community manager purchases/sells from/to all internal peers (MW)

Power output (MW)

Net power (MW)

Total purchased/sold power by peer $i$ (MW)

Binary variable for selling/purchasing status

Total imported/exported traded electricity outside the community

Electricity purchased/sold from/to the DC (MW)

Power output from natural gas/non natural gas/hydro /nuclear/wind/PV units (MW)

\section{Introduction}

For more than a century, the energy supplies have been organized by following a scheme of unidirectional flows, both for energy supply and information flows (U.S. Department of Energy, 2017). This scheme, in general, considers that the electricity is produced from a generator park (located far from the end consumers), and it is transmitted over long distances through high voltage lines. Electricity then passes through distribution stations, where its voltage is reduced, to be transported to end-users via low voltage lines. This traditional scheme is shown in Fig. 1-A. While the system can be considered deeply developed, the annual global investments in the expansion and research of the electricity sector have been increased from USD 430 billion in 2005 to over USD 760 billion in 2018 (IEA, 2019).

However, recently there have been many developments in electricity generation technologies (Schröder, Andreas; Kunz, Friedrich; Meiss, Jan; Mendelevitch \& Hirschhausen, 2013) and smart grids (Dileep, 2020). These developments have made it possible to achieve decreases in production costs and increase the efficiency of the operation of the systems. Currently, several developments have promoted the development of a new concept (in terms of electricity generation and supply). I) The first development was the reduction in costs for the manufacture and installation of photovoltaic (PV) cells (Ardani et al., 2018) and wind turbines in homes (Bahaj et al., 2007). II) Developments in two-way communication between power system elements (Kristov, 2019). III) The participation of new electrical devices, such as electric cars, has been increased during the last years due to the evolution in the autonomy of these vehicles, reductions of their prices, along with a larger product supply by the different car brands (Slowik et al., 2016).

The impact of all these new technologies leads to important changes in the structure of the electricity systems. The new control technologies allow improvements in the communications between the system elements, improve the flexibility of the systems, reduce electricity consumption, and provide a more reliable service. In consequence, new structures of electrical systems must be in concordance with the novel technologies (Huang et al., 2012). In this regard, Fig. 1-B shows a novel system configuration. It considers an adaptation, which is proposed to integrate the traditional large-scale system (one-way 
information, labeled as Conventional End Users in the figure) with the new electric system configuration (two-way information system, labeled as New structure of End Users).

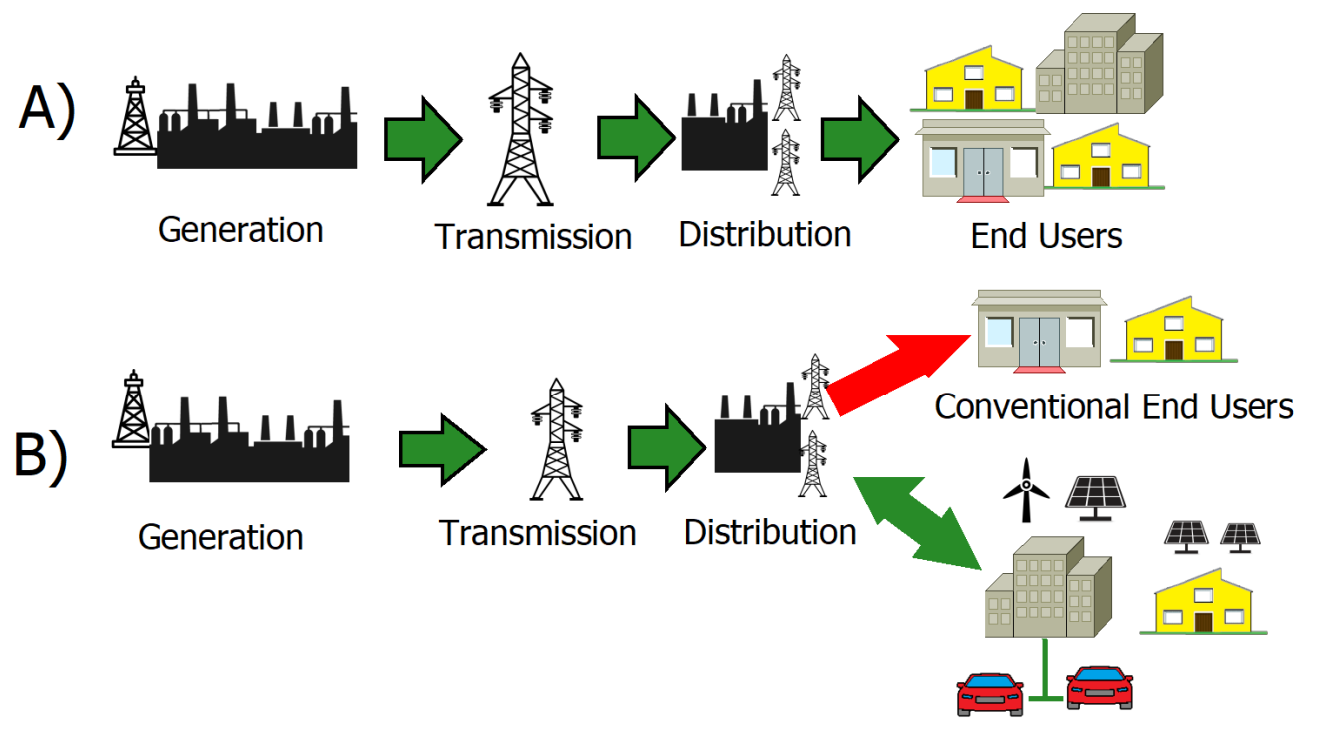

New structure of End Users

Fig. 1-A. The traditional scheme of electricity systems. B. The new scheme of generation and production of the electricity system.

From all emerging information and electricity distribution technologies, the concept of peer-to-peer (P2P) trading was developed (Yebiyo et al., 2020). In this type of market, the participants, called peers, can change their roles as buyers or sellers of electricity. They perform these transactions according to the supply and demand interactions. Peers are considered entities with their economic benefit objectives. The P2P market structure has been studied in the literature, and numerous papers discuss the topic (Hayes et al., 2020; Huang et al., 2012; Kusakana, 2019; Rodrigues et al., 2020; Tushar et al., 2019, 2020). Many researchers agree that a system operator (SO) is needed to provide a secure framework and ensure free competition between peers (Johnston, 2017). Under the SO administration, peers propose their bids (specifying prices and amounts of electricity) they are willing to sell or buy. The offers of each peer are confidential and only the SO can access them. In this context, Electricity Distribution Companies (DC) are included as bidders, participating in the transactions (Liu et al., 2019). Novel schemes started finding successful applications in cases such as the Energiewende system in Germany (Joas et al., 2016), along with emerging technologies. The main advantages of P2P trading are that the electricity produced by each peer can be linked to the profit by competitive economic benefits. The generation stage is considered in concordance with the requirements of the end-users. The optimization of these resources can be enhanced by using a cooperation network between producers and consumers (Park \& Yong, 2017).

The basic process considers that peers submit their bids. Then, the SO analyses the bids and the system status to receive these transactions (for instance, line status). The SO solves an optimization problem (then offsets the price) while the demand and generation are scheduled (according to resource availability (Basnet \& Zhong, 2020)). The compensation price consists of the payment for the amount of energy that the peers offer to buy or sell. It is implemented to ensure all peers in the P2P community gain economic benefit (Long et al., 2018). The compensation price is adopted to favor the peers when they participate in the P2P electricity market. After receiving the compensation price, each peer can accept it or submit a new bid. In the next round, the SO analyses new offers and determines a new compensation price. This process is iterative and ends when there are no more changes to offers (or a certain number of steps are reached). Several papers analyze the price compensation mechanism (Lin et al., 2019; Zhou et al., 2020).

The organization of the P2P market is based mainly on two possible ways: Full P2P bilateral negotiation mechanism and P2P with Community Managers (CMs). In the first case, the SO administers a structure where the bilateral contracts between peers are considered by ensuring free competition and system security. However, under this structure, the hidden costs of participating in the market could be high for a single peer. The risks of a single peer not being able to comply with the contracts are also high. A peer could adopt a very conservative strategy (with low participation in the market) to avoid potential economic losses (and penalties for non-compliance with the contracts). In many systems, there are many systems where the peers are represented by CMs (because of the before drawbacks). This structure can offer several benefits to peers, such as reductions in operating costs and increasing profit margins. Negotiation processes have been studied in the energy industry field. In (Biswas \& Gupta, 2019) the barriers to the adoption and successful implementation of blockchains are studied in 
different industries and services. In (Hasan et al., 2019)a solution for efficient supply chain management involving items shipped via smart containers is developed.

Some related works that attend this kind of electricity trading exist in the bibliography. In Nakayama et al. (2019), the authors present an operational optimization model that minimizes the cost of electricity buyers through smart contracts shared among all the blockchain nodes. (Li et al., 2019) also proposes a blockchain for decentralizing the transaction of electricity applied to microgrids at the distribution level. In (Yebiyo et al., 2020), an initial conceptualization of this novel market is developed by studying the influences of the consumer-peer relationships along with the technology innovations. Authors of (Khorasany et al., 2019) present a bilateral transaction model that addresses the direct interaction of players in the P2P market. Also, Liu et al. (2019) present a review of the main configurations of P2P markets, giving the main characteristics of each one. The authors of Moret and Pinson (2019) develop a decomposition model that addresses the CM optimization problem. Kang et al. (2017) propose a P2P model to perform transactions among hybrid and electric vehicles connected to smart grids. The model satisfies the demand by considering incentives to discharging vehicles to balance the electricity trading. Besides, a promising consortium blockchain technology is included to improve the security of transactions. Finally, in Hug et al. (2015), a micro-grid is solved, where the power demand is covered by using local generation.

Table 1 summarizes the main contributions of the before works and the main differences with this proposal. As can be observed, many approaches consider the interactions in the new structures of the P2P market. However, not many papers consider the link between traditional systems and the new systems previously described. Few works address this link. In this regard, (Wandhare \& Agarwal, 2014) consider the centralized-distributed relationship, but only for PV generation. Besides, the main drawback of the methods that solve large-scale systems, which consider the smart grids, is that the models solve both systems in isolation (Zhou et al., 2014).

A common issue in the literature is the lack of coordination between large-scale systems and small distribution networks. This problem results in economic and operational disadvantages for both systems. Often, it is impossible to cover the demand by using a cheaper source because it is impossible to transmit this flow (when the pre-calculated solution is applied to the real grid). Consequently, the demand must be met less optimally, or, even worse, it cannot be satisfied. In this regard, the authors of (Bell \& Gill, 2018) confirm that it is necessary to improve the coordination between these systems. These affirmations are based on reports of (De Martini et al., 2015) about these inconveniences in their studied systems. However, the largest amount of electricity is generated through large-scale systems at present, despite several authors believe that the smart grids (along with distributed generation) are the key to the future (El-hawary, 2014; Gharavi \& Ghafurian, 2011; Ipakchi \& Albuyeh, 2009; Reka \& Dragicevic, 2018). Consequently, if a smart grid is scheduled in isolation and these results are included in the parameters of the large-scale system to be solved (in a static manner), there are several drawbacks. A possible inconvenience to this methodology is that it fails to schedule properly renewable sources. Furthermore, successful operations of the smart grid are obtained, when holistic analyses are considered, to avoid this issue. The whole system must be considered as integrated, not as isolated portions (Ribeiro et al., 2012).

Table 1

Main contributions and differences of related bibliography

\begin{tabular}{|c|c|c|}
\hline Paper & Main Contributions & Differences \\
\hline $\begin{array}{l}\text { (Yebiyo et al., } \\
2020 \text { ) }\end{array}$ & Conceptualization of the P2P electricity market. & $\begin{array}{l}\text { It describes a model architecture with considerations of the } \\
\text { market at distribution level. }\end{array}$ \\
\hline $\begin{array}{l}\text { (Y. Liu et al., } \\
\text { 2019) }\end{array}$ & A review of the main configurations of $\mathrm{P} 2 \mathrm{P}$ markets. & $\begin{array}{l}\text { Main contribution is giving readers a detailed stat-of-art of the } \\
\text { more extended P2P configurations. }\end{array}$ \\
\hline $\begin{array}{l}\text { (Nakayama et al., } \\
\text { 2019) }\end{array}$ & $\begin{array}{l}\text { Optimization model that minimizes the energy cost through } \\
\text { smart contracts. }\end{array}$ & $\begin{array}{l}\text { Solve the problem through blockchain implementation. It does } \\
\text { not consider integration between large-scale and decentralized } \\
\text { systems. }\end{array}$ \\
\hline (Li et al., 2019) & $\begin{array}{l}\text { Blockchain implementation of decentralized grids at } \\
\text { distribution level. }\end{array}$ & $\begin{array}{l}\text { It does not consider upper electricity levels as transmission and } \\
\text { generation on a large-scale. }\end{array}$ \\
\hline $\begin{array}{l}\text { (Khorasany et al., } \\
\text { 2019) }\end{array}$ & $\begin{array}{l}\text { A novel bilateral transaction model that addresses the direct } \\
\text { interaction of players in the } \mathrm{P} 2 \mathrm{P} \text { market. }\end{array}$ & $\begin{array}{l}\text { It considers the P2P market with full interaction between the } \\
\text { consumers and peers. Implications of a possible connection with } \\
\text { large-scale systems are not included. }\end{array}$ \\
\hline $\begin{array}{l}\text { (Moret \& Pinson, } \\
\text { 2019) }\end{array}$ & $\begin{array}{l}\text { A model that addresses the community manager } \\
\text { optimization problem. Authors consider a system with } 15 \\
\text { peers. }\end{array}$ & $\begin{array}{l}\text { Authors present a decomposition method that divided the original } \\
\text { problem for each peer. The link between decentralized and } \\
\text { centralized systems is not explored. }\end{array}$ \\
\hline (Kang et al., 2017) & $\begin{array}{l}\text { A P2P model for transactions among hybrid and electric } \\
\text { vehicles in smart grids. Demand is satisfied by considering } \\
\text { incentives to discharging vehicles. Blockchain technology is } \\
\text { presented to improve the security of transactions. }\end{array}$ & $\begin{array}{l}\text { The analyzed system is only included into a smart grid. The } \\
\text { COnsortium blockchaiN (PETCON) method does not consider the } \\
\text { nexus between these grids and the traditional large-scale systems. }\end{array}$ \\
\hline (Hug et al., 2015) & $\begin{array}{l}\text { A distributed energy management approach is developed to } \\
\text { coordinate the local generators, loads, and storage systems. }\end{array}$ & $\begin{array}{l}\text { The model is applied in microgrids. Large-scale systems are not } \\
\text { included in the test systems. }\end{array}$ \\
\hline
\end{tabular}

In this context, a new model called the Integrated model (INT), which considers the relationships between both structures, is vitally important. The contributions of the paper are the followings: 
- The new hybrid model combines traditional-centralized electricity production with decentralized-P2P trading with two-way communication. Holistically considering both systems brings economic and operational benefits. The economic benefits arise because, by dynamically considering the integration, scheduling and load dispatch can be adapted more conveniently. In addition, peers can sell their surplus in a larger space, increasing their profit.

- The daily scheduling takes into account no only high power systems but also small-scale elements, improving their efficiency. It means extra operational benefits. The model considers simultaneously, for instance, the effects of a 100 MW generator than the effects of a $1 \mathrm{~kW}$ PV solar roof.

- The model considers stages belonging to traditional systems such as large-scale generation, high-voltage electricity transmission, and energy distribution. It also includes the operation of the smart grids that performs the novel structure, where the interactions among peers, distributors, and small-scale generation takes place (ensuring transparency and confidentiality of data). This work considers the transmission constraints for the high voltage stage (traditional system) and the low voltage stage (decentralized system). The model considers several costs (relating to the energy field) as fuel consumption, operating cost of each source, and costs of the grid using.

The implementation of the proposed model is demonstrated to show the viability and effectiveness of studying a real case. The test system is the integrated Argentine large-scale system and Armstrong smart grid. Results will prove the convenience of applying the novel formulation when they are compared with traditional models in the literature (that address both systems in isolation). Besides, the two classical models, which are preferred in the literature (the full peer-to-peer electricity market P2P-and the Community Manager-CM- models), are also included in detail because this paper offers modifications of these models that enhance their performance. However, the main reason to consider both models is to facilitate the reader's understanding of the characteristics of the INT model. As will be seen in the following sections, presenting in detail the most relevant points of the classic models, the formulation of the INT model will be better understood.

The rest of this paper is organized as follows. Section 2 shows the classic mathematical approaches: the full P2P model and the CM model. Section 3 presents the novel Integrated model. Section 4 details the test system. The results are discussed in Section 5. And several conclusions are given in Section 6.

\section{Classic models that address the peer-to-peer systems}

In this section, the models representing the P2P market relationships will be presented. How the different components interact will constitute the main difference between the models.

\subsection{Full peer-to-peer electricity market $(P 2 P)$ model}

In this type of market, direct trading between peers is predominant. They can freely negotiate the purchasing or selling of electricity. Based on the work of (Hug et al., 2015; Kang et al., 2017; Khorasany et al., 2019), this model can be represented as:

$$
\min S C=\sum_{i}^{T} \sum_{t}^{T} g_{i, t} c g_{i}+\sum_{i}^{I} \sum_{j}^{J} \sum_{t}^{T}\left(p r_{i, j}^{b} x_{i, j, t}+p r_{i, j}^{S} y_{i, j, t}+p r_{i, j}^{g} x_{i, j, t}-p r_{i, j}^{g} y_{i, j, t}\right)
$$

where Eq. (1) is the objective function that represents the social cost of the problem. The selling/purchase price $p r_{i, j, t}^{S} / p r_{i, j, t}^{b}$ is a constant related to the peer and market characteristics. Determination of the price is deeply discussed in (N. Liu et al., 2017). The traded electricity variable $\left(x_{i, j, t} / y_{i, j, t}\right)$ results from the difference between peer demand $\left(d k t_{i, t}\right)$ and generation of each peer $\left(g_{i, t}\right)$.

Demand constraint (2) determines that the production of generators and the available electricity must cover the demand. Where $\operatorname{distr}_{\text {comp }}^{b}$ i,t is the electricity amount that each peer buys to the Distribution Company (DC).

$$
\sum_{i}^{I} d k t_{i, t}=\sum_{i}^{I}\left(g_{i, t}+\operatorname{distr}_{\text {comp }_{i, t}}\right) ; \quad t=1, \ldots, T
$$

Constraint (3) establishes that the electricity transmitted through lines is limited by their maximum capacity $\left(\overline{p_{l, J}^{l}}\right)$, and the circulation in both directions is admitted.

$$
-\overline{p_{l, j}^{l}} \leq p_{i, j, t}^{l} \leq \overline{p_{l, j}^{l}} ; i=1, \ldots, I ; j=1, \ldots, J ; t=1, \ldots, T
$$


In addition, constraints (4-7) model the trading of electricity.

$$
\begin{array}{lc}
x_{i, j}^{\min } \leq x_{i, j, t} \leq x_{i, j}^{\max } ; & i=1, \ldots, I ; j=1, \ldots, J ; t=1, \ldots, T \\
x_{i, j, t}+x_{j, i, t}=0 ; & i=1, \ldots, I ; j=1, \ldots, J ; t=1, \ldots, T \\
x_{i, j, t} \geq 0 ; & i=1, \ldots, I ; j=1, \ldots, J ; t=1, \ldots, T \\
y_{i, j, t} \leq 0 ; & i=1, \ldots, I ; j=1, \ldots, J ; t=1, \ldots, T
\end{array}
$$

where Eq. (5) ensures that the net transaction between peers $i$ and $j$ is 0 . Sign assumptions are established in Eq. (6) and Eq. (7), the purchased electricity is positive, and the sold one is negative. In addition, each bus of the system is balanced in constraint (8), which is presented as follows:

$$
-\sum_{i \in b u}^{I} g_{i, t}+\sum_{i \in b u}^{I} p_{d t k_{i, t}}+\sum_{i \in b u}^{I} p_{-} n e t_{i, t}=0 ; \quad t=1, \ldots, T
$$

The net power $\left(p_{-} n e t_{i, t}\right)$ is the amount of electricity available or required depending on its value. In this regard, constraint (9) constitutes the variable by using two components: the total selling electricity of peer $i\left(t_{-} y_{i, t}\right)$ that is the available amount to be sold if the value of $p_{-} n e t_{i, t}$ is positive. And the total purchasing electricity of peer $i\left(t_{-} x_{i, t}\right)$ that is the required amount if the value of $p_{-} n e t_{i, t}$ is negative.

$$
p_{-} n e t_{i, t}=t_{-} y_{i, t}-t_{-} x_{i, t} ; \quad i=1, \ldots, I ; t=1, \ldots, T
$$

The variables $t_{-} y_{i, t} / t_{-} x_{i, t}$ are related to the trading variables of selling $\left(y_{i, j, t}\right) /$ purchasing $\left(x_{i, j, t}\right)$ between peers $i$ and $j$ by constraints (10-13).

$$
\begin{array}{ll}
t_{-} x_{i, t}=\sum_{j}^{J} x_{i, j, t} ; & i=1, \ldots, I ; t=1, \ldots, T \\
t_{-} y_{i, t}=\sum_{j}^{J} y_{i, j, t} ; & i=1, \ldots, I ; t=1, \ldots, T \\
t_{-} x_{j, t}=\sum_{i}^{I} x_{i, j, t} ; & j=1, \ldots, J ; t=1, \ldots, T \\
t_{-} y_{j, t}=\sum_{i}^{I} y_{i, j, t} ; & j=1, \ldots, J ; t=1, \ldots, T
\end{array}
$$

Constraints (14-17) ensure the correct working of binary variables $u_{-} s e l l_{i, t}$ and $u_{-} b u y_{i, t}$ that correspond to the selling and purchasing peer status, respectively. $u_{-} s e l l_{i, t}$ is equal to 1 when the net power is greater than 0 , and 0 otherwise. An inverse situation occurs by using $u_{-} b u y_{i, t}$. And $\mathrm{M}$ is a large positive number.

$$
\begin{gathered}
-M\left(1-u_{-} \text {sell }_{i, t}\right) \leq p_{-} n e t_{i, t} \leq M\left(u_{-} \operatorname{sell}_{i, t}\right) ; \quad i=1, \ldots, I ; t=1, \ldots, T \\
-M\left(u_{-} b u y_{i, t}\right) \leq p \_n e t_{i, t} \leq M\left(1-u_{-} b u y_{i, t}\right) ; \quad i=1, \ldots, I ; t=1, \ldots, T \\
-M\left(1-u_{-} b u y_{i, t}\right)-p_{-} n e t_{i, t} \leq t \_x_{i, t} \leq M\left(1-u_{-} b u y_{i, t}\right)-p_{-} n e t_{i, t} \\
i=1, \ldots, I ; t=1, \ldots, T
\end{gathered}
$$




$$
\begin{array}{r}
M\left(1-u_{-} \operatorname{sell}_{i, t}\right)+p_{-} n e t_{i, t} \leq t_{-} y_{i, t} \leq M\left(1-u_{-} \text {sell }_{i, t}\right)+p_{-} \text {net }_{i, t} \\
i=1, \ldots, I ; t=1, \ldots, T
\end{array}
$$

In order to solve the problem with the P2P model, several techniques have been implemented in the literature, in concordance with the spirit of the decentralized distribution of the problem. Some of these techniques are mentioned in (Sorin et al., 2019). Fig. 2 shows the scheme of this model. However, in this paper, the problem is solved by using a Mixed-integer Linear Programming (MILP) model that minimizes the social cost as was described in (1) and subject to (2-17). In addition, the model assumes that the discussion between the peer that buys electricity and the peer that sells it is solved during one step. This assumption is based on the fact that trading prices were previously accorded by all peers. In this context, the SO receives all bids and solves the problem.

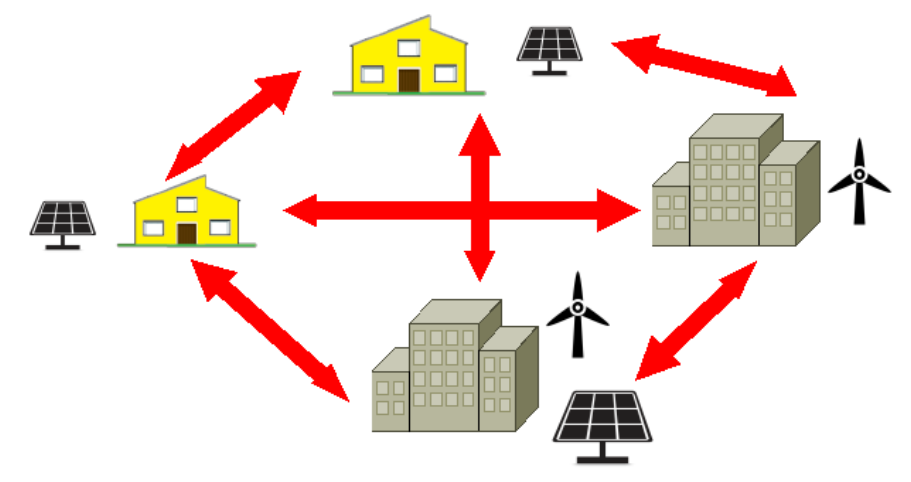

Fig. 2. Full P2P model scheme

\subsection{Community Manager (CM) Model}

When a full P2P market model is utilized, some peers can have several issues to address the required demand. In consequence, their participation as bid makers in the grid can be dramatically reduced, in order to avoid potential penalties due to possible deviations in the agreed contract. To face the issues of non-compliance with the contracts, the concept of electricity trading with Community Managers (CMs) is introduced. In consequence, a MILP model that minimizes the SC variable of the objective function (18) based on the trading between CMs is presented as follows:

$$
\min S C=\sum_{t}^{T} \sum_{c}^{C} \sum_{i}^{I}\left(\operatorname{prc}_{i, c}^{b} \rho_{i, c, t}+\operatorname{prc}_{i, c}^{S} \sigma_{i, c, t}+\operatorname{prc}_{i, c}^{g} \rho_{i, c, t}+\operatorname{prc}_{i, c}^{g} \sigma_{i, c, t}\right)+\sum_{t}^{T} \sum_{c}^{C}\left(p r_{c, d}^{t} \mu_{c, d, t}^{i m p}-p r_{c, d}^{t} \mu_{c, d, t}^{e x p}\right)
$$

Constraints (2-9), and (14-17) are also implemented. In addition, constraints (19-22) define the rest of the model. In concordance with the concept of task delegation to the CMs, if a peer decides to trade with another peer, who is outside of the community, the transaction must be performed through the CM. In this regard, constraint (19) establishes that the sum of the electricity amount that all peers, included in the community $\omega$, buy from the CM is equal to the variable $\gamma_{c=\omega, t}$. Similarly, (20) establishes that $\delta_{c=\omega, t}$ represents the total amount that all peers sell to the CM of its community $\omega$.

$$
\begin{array}{ll}
\sum_{i \in \omega}^{I} \rho_{i, c=\omega, t}=\gamma_{c=\omega, t} ; & t=1, \ldots, T \\
\sum_{i \in \omega}^{I} \sigma_{i, c=\omega, t}=\delta_{c=\omega, t} ; & t=1, \ldots, T
\end{array}
$$

Constraint (21) determines the electrical balance of the community. It establishes that the sum of the electricity entering the community is equal to the sum of the electricity leaving the community. Where $\operatorname{distr}_{\text {comp }}{ }_{c, t} / \operatorname{distr}_{\text {comp }}{ }_{c, t}$ represents the variable related to the electricity transactions with the peer that represents the DC. Fig. 3 illustrates the scheme of the CM model.

$$
\begin{array}{r}
\operatorname{distr}_{c o m p}^{b, t}+\delta_{c, t}+\sum_{d}^{D} \mu_{c, d, t}^{i m p}=\operatorname{distr}_{c o m p}{ }_{c, t}^{s}+\gamma_{c, t}+\sum_{d}^{D} \mu_{c, d, t}^{e x p} \\
c=1, \ldots, C ; t=1, \ldots, T
\end{array}
$$




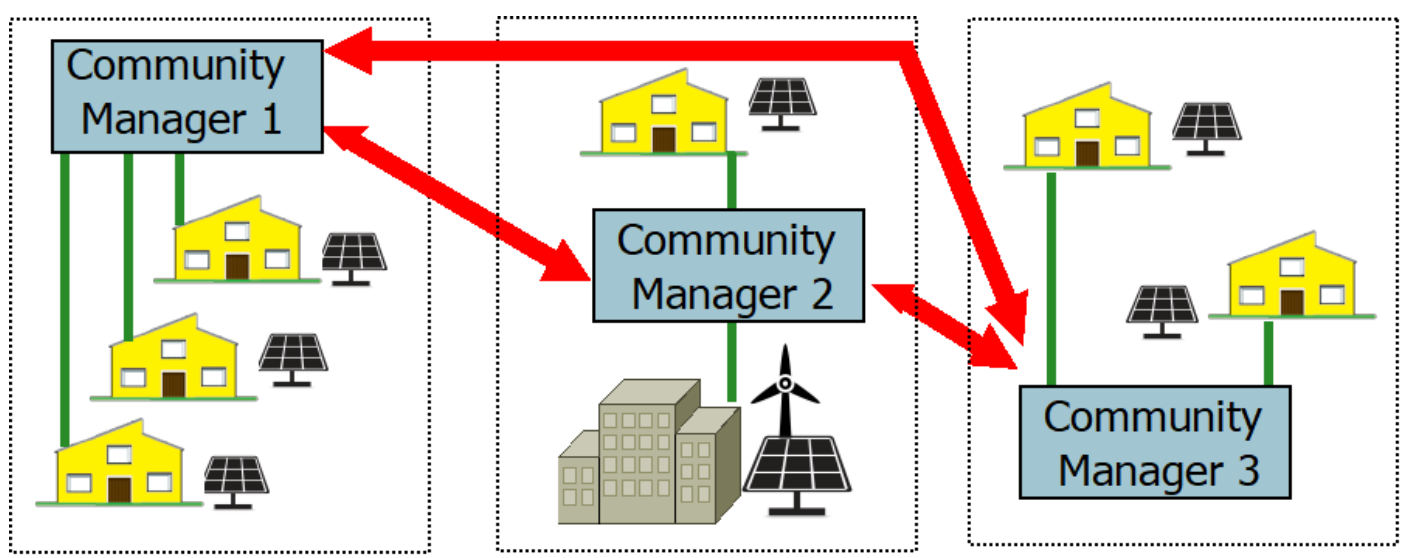

Fig. 3. Community manager (CM) model scheme

\section{Integrated model (INT)}

Nowadays, decentralized systems composed of smart grids are not very common, and the vast majority of the users are supplied with classical large-scale systems. These systems are composed of generating units that work using different sources. Usually, generating units are far from consumption centers. As a consequence, the generation is transmitted through large distances by using high voltage lines. Distribution stations are located close to the centers, they adequate the electricity ensuring that it arrives at final costumers. Large-scale systems are mainly characterized by the central control of the Independent System Operator (ISO). While the specific activities of ISOs can vary between different countries (especially between European and American countries), the main functions of ISOs are the application of market rules, ensuring competence, establishing the optimal load dispatch, and the control of all the market participants. However, the current technologies allow the integration between large-scale centralized systems and decentralized ones.

\subsection{Large-scale system-smart grid. Model formulation}

The complete formulation of the large-scale system model is detailed in (Alvarez, 2020) (sections 2.1-2.5 and 2.7). The BSL (Block System Linear) model includes constraints related to the demand, spinning reserve, power output limits for thermal units, hydro generation, PV generation, wind generation, nuclear generation, and transmission. Formulations in this paper deal with the effects of day-ahead, considering the ISO management for large-scale generation and transmission of electricity. Constraints of some types of generation sources are originally nonlinear. Consequently, the elevated computational effort in large-scale systems is an important inconvenience for solving their scheduling. According to the above, the BSL model attends to the nonlinear constraints by ensuring an accurate level of solution. Besides, the capacity of the model to divide the large systems into generating blocks reduces the computational effort by obtaining feasible solutions with efficient times. Therefore, the novel model of this section integrates a large-scale system with the peer-to-peer market model. The BSL model is selected to model large-scale systems because it combines the main energy sources globally: thermal generation with liquid and solid fuels, natural gas-fired units, hydro generation, wind, PV, and nuclear. Because of the above, the objective function that addresses the operating cost is presented in Eq. (22).

$$
\min \text { cost }_{\text {large scale }}=\sum_{b u}^{B U} \sum_{g u=1}^{G U}\left(p_{g u, b u, t}^{g} \delta^{g}+p_{g u, b u, t}^{n g} \delta^{n g}+p_{g u, b u, t}^{h} \delta^{h}+p_{g u, b u, t}^{n} \delta^{n}+p_{g u, b u, t}^{w} \delta^{w}+p_{g u, b u, t}^{p v} \delta^{p v}\right)
$$

The Integrated P2P model (INT) combines the formulations of sections 3.1-3.2. When the social cost of smart grids is related to a large-scale system, the objective function is Eq. (23). This objective function is obtained from the combination of (1) and (18). It considers transactions between peers located inside the community, between peers inside and outside the local community, and between CMs and ISOs. The latter is connected to smart grids through DCs. The first term of the objective function is the cost of the internal generation (cost of producing electricity with generations that belong to each peer), the second term is the cost of full $\mathrm{P} 2 \mathrm{P}$ transactions, and the third term is the CM trading cost.

$$
\begin{aligned}
& \min S C=\sum_{i}^{T} \sum_{t}^{T} g_{i, t} c g_{i}+\sum_{i}^{I} \sum_{j}^{J} \sum_{t}^{T}\left(p r_{i, j}^{b_{-} d i f f} x_{i, j, t}+p r_{i, j}^{s} y_{i, j, t}+p r_{i, j}^{g} x_{i, j, t}-p r_{i, j}^{g} y_{i, j, t}\right) \\
& +\sum_{t}^{T} \sum_{c}^{C} \sum_{i}^{I}\left(p r c_{i, c}^{b_{-} d i f f} \rho_{i, c, t}+\operatorname{prc}_{i, c}^{S} \sigma_{i, c, t}+\operatorname{prc}_{i, c}^{g} \rho_{i, c, t}+p r c_{i, c}^{g} \sigma_{i, c, t}\right)+\sum_{t}^{T} \sum_{c}^{C}\left(p r_{c, d}^{t} \mu_{c, d, t}^{i m p}-p r_{c, d}^{t} \mu_{c, d, t}^{e x p}\right)
\end{aligned}
$$


It can be observed that constant $p r_{i, j}^{b \text { diff }}$ is the differentiated price (USD/MWh) that can be obtained when the large-scale system is connected with the smart grid. When the demand of the smart grid is not met by the internal generation capacity, the grid must import electricity. In this context, if the mathematical model that represents the operation of the large-scale system considers the demand of the smart grid as variable, the importation cost that DC must pay to the ISO could be reduced. In consequence, all peers can be benefited from the value of $p r_{i, j}^{b_{-}}$diff because the DC, which trades with peers and CMs, is also benefited from the interaction with the ISO. The model of this section includes several constraints that were presented in the two previous sections. The objective function (23) is subject to constraints (2-17) and (19-21). Fig. 4 illustrates the structure and the interaction between components of the complete model. The relationship between the model of the largescale system and the smart grid will be discussed and exemplified in the next section.

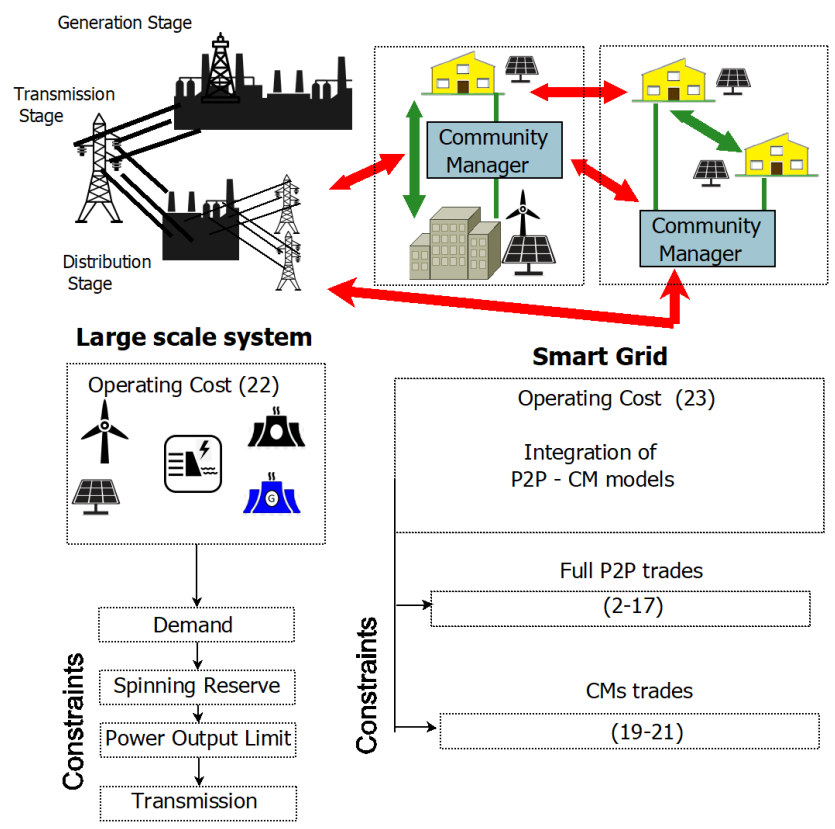

Fig. 4. Scheme of the model that relates the large-scale system and smart grid. INT model

\subsection{Enhancing of electricity transactions and contributions of the INT model}

Several points distinguish the INT model from similar ones presented in the literature. Most of the differences were marked in the Introduction. However, in this subsection, other points are highlighted. It should be clarified that the complete INT model is not only composed of the formulation presented in this paper but is also formed by other constraints (that have already been developed in the literature and have been duly cited in the corresponding section).

In the present work, only the constraints that are new to the state of the art have been presented. This was prepared in order not to overextend the content and facilitate the reader's understanding. Even in the description of the P2P and CM models (which are not the main contribution), novel formulations are introduced. This is the case of the constraints (4-7), (10-17), and (19-20). They are based on activations and deactivations using auxiliary variables. These constraints are important because they allow maintaining the nature of the type MILP for the implemented models. This differentiates this proposal from others that consider nonlinear constraints that increase computational times. It also differentiates the proposal from others that use decomposition techniques to reduce computational times, but present the risk of leaving an optimum out of the search process. As detailed in (Lima \& Grossmann, 2011), the MILP models have the advantages of presenting reductions in computational time, flexibility to add constraints, and ensures the global optimum.

Besides, the model of (Alvarez, 2020) presents several linearization techniques. They have a sufficient level of approximation, according to the evaluations that have been made in this work. The present work takes the mentioned paper as a starting point. This previous work includes linearization techniques that correspond to conventional hydropower generation and pumped storage units. Non-linearities of these units include the operating curves (power output vs. hydraulic head vs. water discharge) and the pumping operation. The previous paper also considers the non-linearities and the head effects in the pumping mode. They are not often considered in the literature. Original constraints that represent the high voltage power transmission are also non-linear. In addition, the thermal unit fuel consumption constraints are non-linear and the paper also linearizes them by implementing linear convex sub-estimations. If all the mentioned constraints are considered, in addition to the new ones from the present paper, the amount of total formulas is higher than 60. In this context, it will be hard to follow this proposal. As a consequence, the author decided only to include in the present work the constraints that are novel in comparison with the previous approaches. 
In addition to the above, the formulation of the INT model presented in Section 3.1 includes the necessary constraints to establish the link between large-scale systems and smart grids. This is not just a mere annexation of more factors concerning the smart grid. It is a whole new development to be able to achieve the operation of both types of systems efficiently using interdependent formulations. This is one of the major contributions of the work and differs from most of those presented in the literature, which does not consider the dynamics of both systems at the same time. Often, the scheduling of the electric system is performed by considering, in a primary stage, the scheduling of the large-scale system, and in a secondary stage, the dynamics of the smart grid. This leaves the smart grid very limited and makes it lose its ability to increase the efficiency of the whole system.

\section{Test system}

The selected test system is composed of the Argentine Electricity System (SADI by its Spanish acronym) with an installed capacity of over 38,000 MW. The system is divided into nine geographic regions, they are: Gran Buenos Aires, Litoral, Noroeste, Cuyo, Noreste, Buenos Aires, Patagonia, Comahue, and Centro. More than $50 \%$ of the electricity demand is required by Gran Buenos Aires- Buenos Aires regions, in concordance with the major portion of the population. In the electricity market, there are a lot of generation companies that can be public, private, or mixed entities. The energy matrix of the country is composed of fossil sources $63.8 \%$, hydropower generation $29 \%$, nuclear fuels $4.7 \%$, and rest of renewables $4.8 \%$ (wind generation $53 \%$, hydro lower than $50 \mathrm{MW}$ capacity $33 \%$, PV $8 \%$, biomass-biogas $5.9 \%$ ). It is noticed that natural gas is the most important source for thermal generation representing over $90 \%$ of fossil fuels. The main scheme of the SADI is composed of 15 buses (E1-E15). The one-line diagram can be observed in Fig. 5.A and all related data can be found in the Appendix of (Alvarez, 2020).

Regarding the smart grid, it is located in Armstrong city, which is placed in Santa Fe province (marked in Fig. 5.A with a yellow triangle), with a population of 12,000 residents. The local DC (called CELAR) has 5,600 users and a peak electricity consumption of $8.4 \mathrm{MW}$. In addition, $34 \%$ of its demand belongs to the residential category, $26 \%$ commercial, $32 \%$ industrial, and $7 \%$ of rural customers. This location has been chosen for implementing one of the first experimental smart grids in the country. It presents micro-generation of small wind farms, PV panels, and a solar park of $200 \mathrm{~kW}$ (Guido, 2018 ; Talpone, J. I., Puleston, P. F., Cendoya, M. G. Battaiotto, 2016). The grid has been organized as been shown in Fig. 5.B, for didactic purposes, with 12 buses (namely B1-B12), 19 peers (P1-P19), 11 lines, and 4 communities. Peer 18 is in charge of the solar park operation. The large-scale system is related to the smart grid through Bus 12 where the DC is located. The company is represented by peer 19 and is connected to the SADI by the large-scale bus E7. The generation technologies that correspond to each peer are indicated in the figure. A natural gas turbine has been included in communities 1-3 to ensure the feasibility of the model.
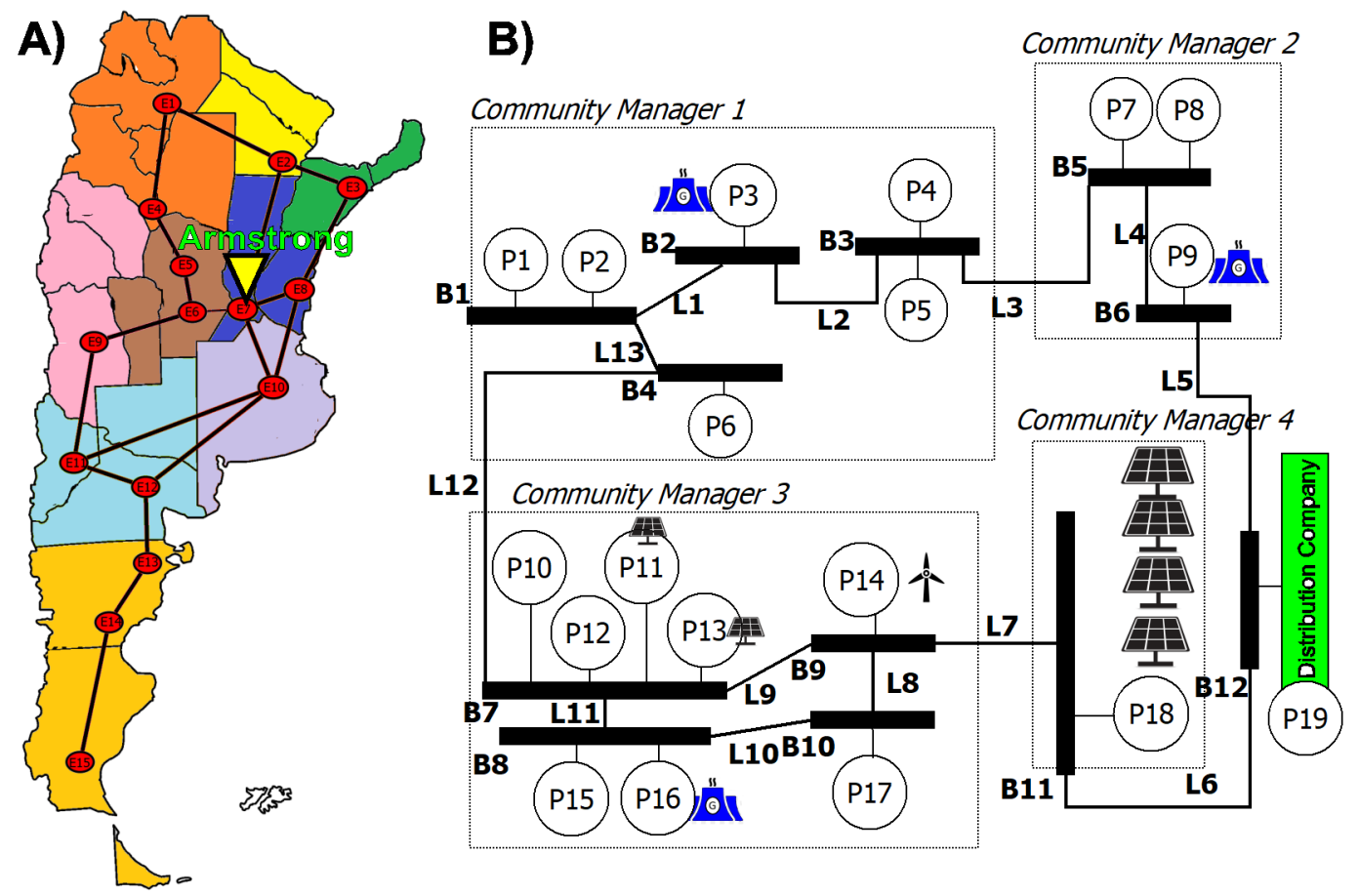

Fig. 5. A) Test system. Argentine large-scale system. B) Armstrong smart grid. 
The three models (presented in Sections 3.1-3.3) have been studied. For the first one (P2P model) limits between communities are not taken into account. For the second one (CM model) the trading between communities is promoted. Lastly, the third model utilizes both previous costs to represent interactions among peers and communities. Information about PV generation is presented in the Table A.1 of the Appendix (generation during hours 1-7 and 21-24 is 0) and of wind generation is in Table A.2. Data relating to the consumption of peers are presented in Table A.3. The information about the grid is based on the real case. However, some data have been modified to obtain feasible solutions.

\section{Numerical results and discussion}

Mathematical models were tested using CPLEX (IBM ILOG CPLEX Optimizer. Version 12.3.0.0. Jul 2011., 20 C.E.) under GAMS (Bussieck \& Meeraus, 2004) on a computer with an A6-3400M AMD processor with 8 Gb of RAM. The time horizon of the study is one day, the time unit is one hour and the relative gap is 0.0005 . In the first case, the full peer-to-peer model (P2P, presented in section 3.1) is represented by (1-17) and composed of 27,121 equations, 20,617 single variables, and 912 binary variables. The total social cost is 6,514 USD and the computational time is 0.5 sec. Table A4 shows the electricity purchase prices for the peers and Table A5 the prices for the selling. As can be observed in the table, purchase prices between peers closer to each other are lower than prices of peers farther apart. The situation with selling prices is inversely proportional, with higher prices between closer peers. This characteristic of prices is designed to promote trading between closer peers because this action reduces the risk of line overloads. This risk is increased when electricity trading fluctuates between short and large distances. Besides, there is an extra cost of using the main grid for trades between peers. This cost is presented in Table A6 and it is noticed that the cost of trading with the DC is lower than the cost for trading with the rest of the peers. It is due to two main reasons: I) the fact that the DC is in charge of the maintenance and operation of the lines, and II) for promoting the trading between peers that are different from distribution companies. In Fig. 6 can be appreciated the electricity trading between peer 19, which represents the DC, and the rest of the peers. The figure shows how the DC sells the required electricity to its peers. Peers that require more electricity amounts are 10- 13 and 15-17. They require 2648, 2117, 2648, 2451, 2084 , and $2401 \mathrm{kWh}$ during the entire programming horizon, respectively. The mentioned peers represent the major portion of users. By contrast, the peers that require the lowest amount of electricity from the DC are peers 8 and 10 , with 53 and 48 $\mathrm{kWh}$, respectively. These peers contain a low number of users. Lastly, peer 18 does not buy electricity from the DC. It only buys electricity from peer 14 during hours 1-8 and 20-24. For the rest of the hours, the peer sells electricity to other peers because it is in charge of the $20 \mathrm{~kW}$ PV power plant.

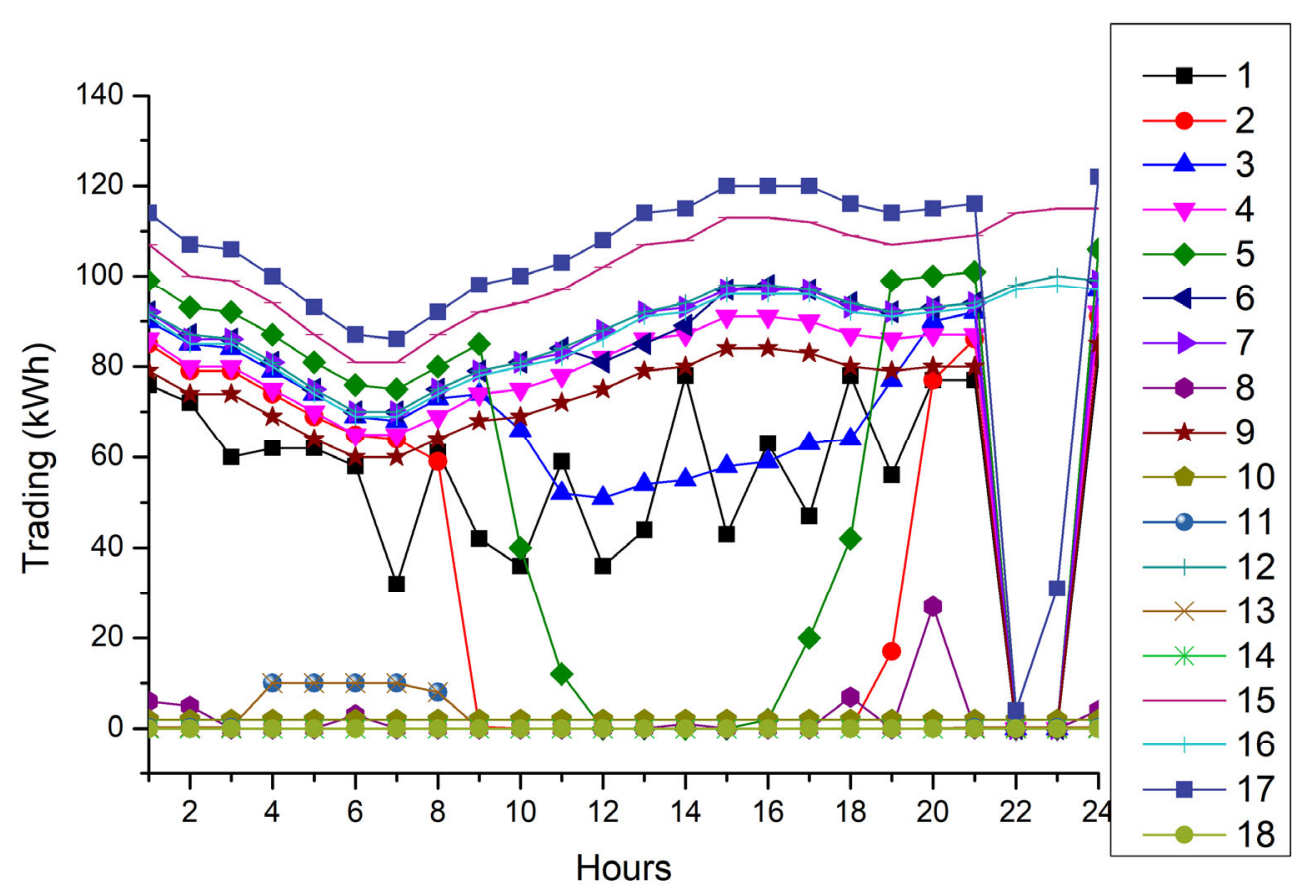

Fig. 6. Electricity trading between peer 19 (the DC) and the rest of them. P2P model

In the second case, the system is solved by using the community manager model (CM). It is composed of 25,777 equations, 7,897 single variables, and 912 binary variables. The social cost is USD 4,599 and the CPU time is 0.4 sec. As a result of the electricity trading through CMs, peers might obtain several economic advantages. CMs have greater political power than a single peer to negotiate with the DC. Consequently, lower purchase prices and higher selling prices are obtained. However, in this case, to prove the benefits of the CM model in comparison with the P2P model, the buying costs of peers that correspond to the same community in Table A7 are very similar to costs expressed in Table A4. Besides, the costs between peers that are 
located in different communities are very high to promote the trading between the inside peers and the corresponding CM. Similar reasoning is observed in Table A8 with the selling prices for the CM model. Working with a CM also brings other advantages as reductions in cost for using the main grid. Table A9 shows the costs for using transmission lines of the DC, and these costs are lower than the costs of Table A6 for peers that belong to the same CM. In addition, the model considers costs for trading between CMs, and they are presented in Table A10. The larger distance between CMs, as higher the trading cost. Notwithstanding these costs between CMs, all peers are beneficed in comparison with the previous model due to substantial profits than the trading between CMs reaches. In addition, Fig. 7 illustrates the main results that are obtained with the CM model. Fig. 7. A) shows the curves that represent the electricity that CM sells to inside peers. CM 1 registers the highest amount of electricity during the whole time horizon, $12,130 \mathrm{kWh}$, because the peers represented by this CM (peers 1-6) are not available to generate electricity. However, CM 4 has the lowest amount with only $41 \mathrm{kWh}$. This low amount is due to CM 4 has a few users and the generation of the PV solar power plant. By contrast, Fig. 7. B) shows the amounts that the CMs buy from their represented peers. These purchases can be used to sell to other internal peers or other CMs. Indeed, CM 3 buys the generation from peers 11, 13, and 14, while CM 4 buys the generation from peer 18. Generation purchased by CM 3 is sold to internal peers that do not generate electricity. However, the generation purchased by CM 4 cannot be sold to another internal peer because CM 4 only represents peer 18 . Consequently, the purchased electricity by this CM is sold to other CMs.
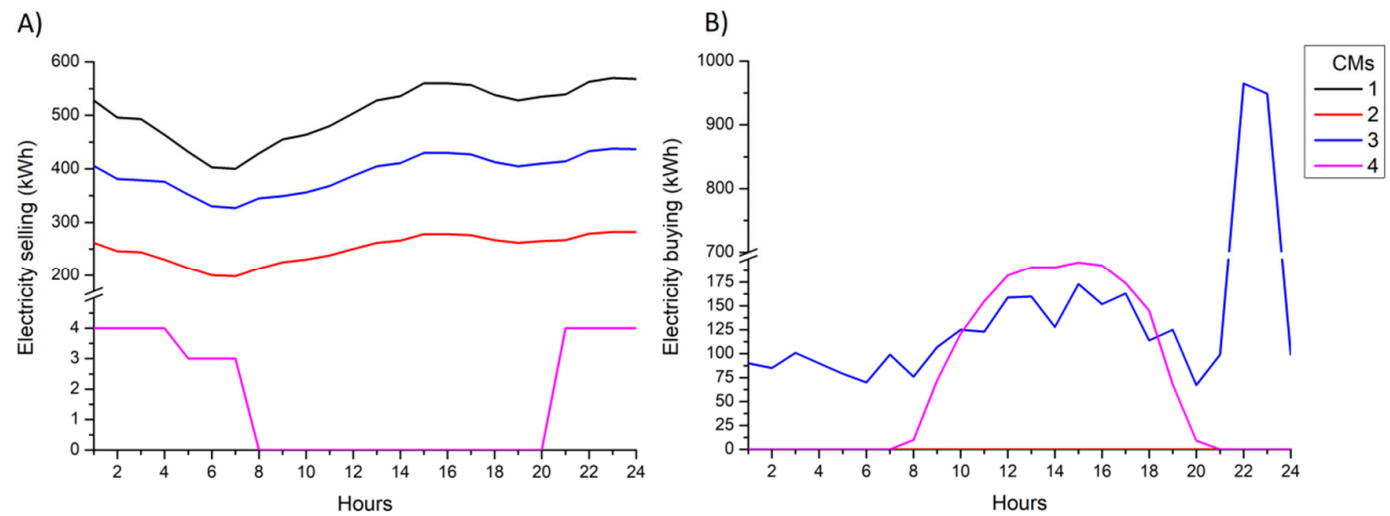

Fig. 7. A) Electricity that CMs sell to inside peers. B) Electricity that CMs buy from their peers. CM model.

For the third case, the system is solved by using the integrated model (INT). It is important to mention that the results for the two previous cases (P2P and CM models) have represented the social cost of operating the smart grid in isolation. As previously appointed, both cases obtain the major part of the consumed electricity from the DC, and this company is supplied by the large-scale system (SADI). In these cases, models do not consider the simultaneous operation of both systems (the large-scale system and the smart grid). In order to obtain the total cost, the cost of the large-scale system is obtained by using the BSL model without considering the hourly consumption of the whole smart grid in the bus E7. Then, the social cost of the smart grid in isolation that is solved by applying the P2P or CM model is added. In this context, the operating cost of the large-scale system is USD 7,751,156 and the BSL model is composed of 12,361 equations, 8,353 single variables, and 1,392 binary variables. As a result, when both costs for both systems are added in isolation, the total costs are USD 7,757,670 for the P2P model and USD 7,755,755 for the CM model. By contrast, when the INT model is considered, the cost of the smart grid in isolation is USD 4,374 (using the objective function (23)) and the cost for the integrated large-scale system and smart grid is USD 7,752,080 (using (22)). The composition of the INT model is 38,139 equations, 16,251 single variables, and 2,304 binary variables. The CPU time is $1.4 \mathrm{sec}$.

Fig. 8 A) shows the generation profile of the large-scale system that is obtained by using the INT model. The figure indicates that the major proportion of the generation corresponds to the hydraulic source with a total of 193,785 MWh during the programming horizon. The second source in importance is natural gas because the country has made great growth in building the infrastructure necessary for the development of this fuel. The total generation with natural gas technology is 126,494 $\mathrm{MWh}$. The rest of the sources constitute $49 \%$ of the total generation. As regards the latter, thermal generators with fossil fuels different from natural gas produce 11,779 MWh. The nuclear source produces 42,120 MWh. Lastly, wind and PV plants only produce 7,394 and $462 \mathrm{MWh}$, respectively. Fig. 8 B) shows the generation profile of the smart grid. In the profile can be appreciated that the grid receives the major amount of electricity from the DC. Results show that the company sells to CMs $21,500 \mathrm{kWh}$. The peers that compose the grid only produce electricity from wind and solar sources. Consequently, the wind generation during the whole programming horizon is $3,792 \mathrm{kWh}$ and the PV generation is $660 \mathrm{kWh}$. The natural gas turbines belonging to some peers do not generate electricity due to the costs of using these units are higher than purchasing electricity from the DC.

To compare the performance of the three models, Fig. 9 presents the hourly cost of each model in the left vertical axis and the grid demand in the right vertical axis. Only the social costs of the smart grid are analyzed in the figure. It can be observed that 
the curve of the P2P model is at an upper-cost level in comparison with CM and INT models. The hourly average of the difference between curves of $\mathrm{P} 2 \mathrm{P}$ and $\mathrm{CM}$ model is USD/h 83. And the average between $\mathrm{P} 2 \mathrm{P}$ and INT model curve is USD/h 96. These differences also can be appreciated in the values of objective functions that were previously announced. The cost of the P2P model is about 33\% higher than the cost with the CM model and 33\% higher than the INT model. By contrast, the curves of CM and INT models are very similar. The curve of the INT model is about USD/h 10 lower than the CM curve during each hour. Regarding hourly costs, results indicate that the costs of the three models vary in concordance with the consumption. Indeed, costs are higher between hours 17 to 24 . This time matches with the higher values of demand. The peak of the hourly cost of the P2P model is produced at hour 23, and the peaks for CM and INT models are produced at hour 24.
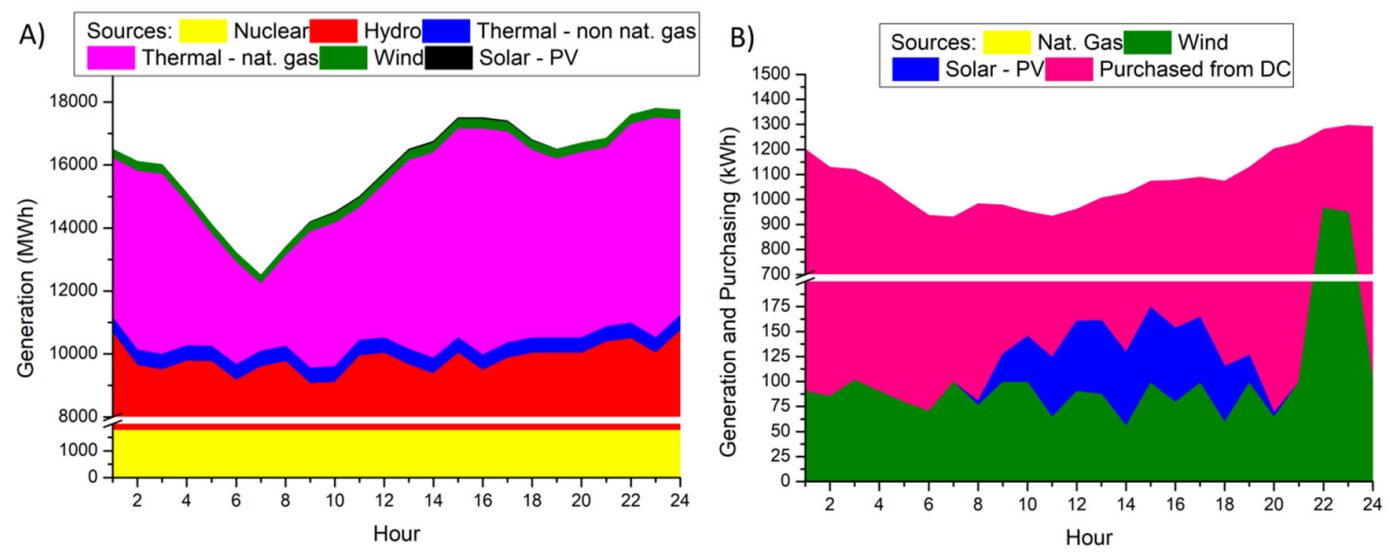

Fig. 8. A) Generation profile of the large-scale system. B) Generation profile and purchasing of smart grid. INT model.

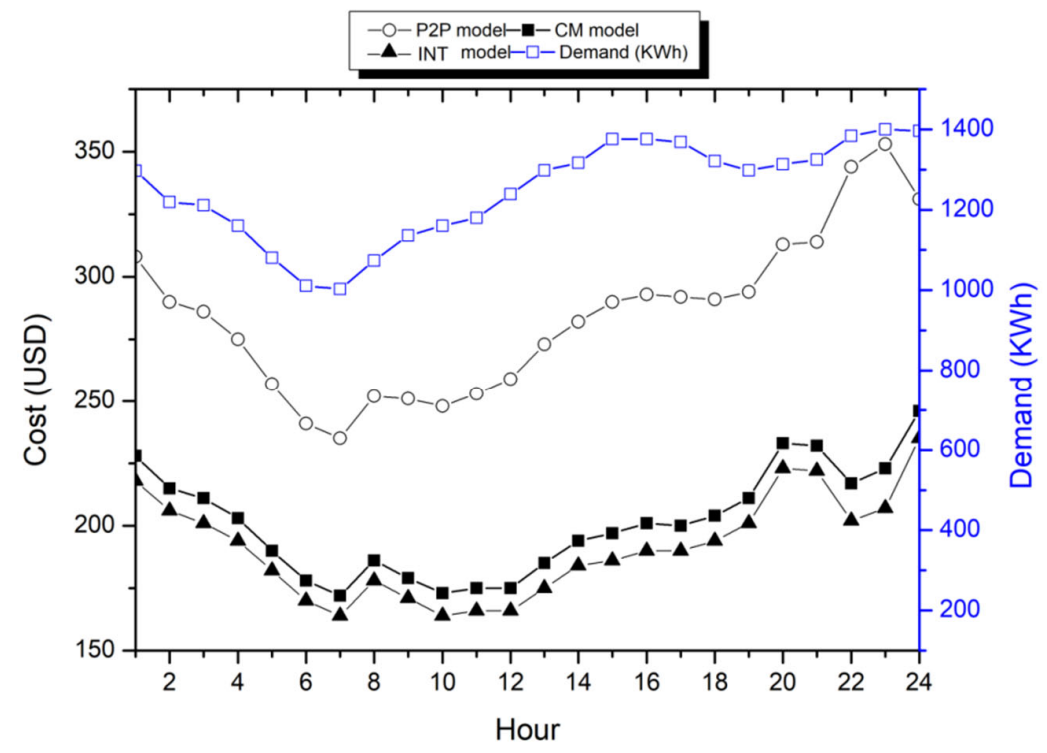

Fig. 9. Comparison of hourly cost among three models.

It is important to mention that the decrease in the cost of production with the INT model is not due to any reduction in cost parameters. In fact, the INT model obtains a cost reduction by virtue of the greater freedom of operation it offers, compared to the P2P and CM models. The INT model uses the same parameters as the previous models presented in Table A.1-A.10. The main reason for the cost reduction is the obtained freedom. Consequently, a peer can choose to trade with the distribution company, through a community manager, or directly with the other peer.

Thanks to this model, a peer can find it more convenient to trade directly with another peer at a certain time. For example, perhaps at some point, a peer has a surplus that their CM cannot trade due to the saturation of the other peers they manage. For this instance, it is more convenient for both peers (the one who buys and the other who sells, both from different communities) to make the transaction directly between them. It should not be confused in any way that the reduction in operational cost with the INT model is due to the use of other parameters (lower than in the previous cases). Furthermore, this 
arises from the fact that by using the new formulation, the number of possible transactions that could reduce the production costs is increasing.

\section{Conclusions}

This paper presented three models that address the electricity trading problem under the peer-to-peer market structure. Models minimize the social cost of the smart grid of generating and trading electricity to satisfy the demand of all peers that compose the grid. The two first models attend the more common kinds of peer-to-peer markets: the full peer-to-peer market model (P2P), which considers that all peers can trade freely on the whole grid, and the Community Manager model (CM), where the trading is performed by CMs that represent the peers. These models present a novel formulation that distinguishes them from many models available in the literature that solve the P2P problem by using several decomposition techniques. The main problems of applying these techniques imply that the scenarios with possible solutions are reduced and it can lead to obtaining solutions that are not global optimums. The test system is a real smart grid called Armstrong, located in Santa Fe province, in Argentina. The grid has about 5,600 users, along with wind and PV generation. When the two models are compared, the CM model reaches a feasible solution about 30\% lower than the P2P model solution. The decrease in the social cost is due to the advantages that constitute this kind of trading. This model puts the peers in a much better position to negotiate with the rest of them and with the Distribution Company (DC), improves his competitive position in the market, and increases their profits.

However, the major contribution of this paper is the introduction of an integrated method that studies the large-scale systems, characterized by centralized and vertical control, and the smart grids, characterized by decentralized control and P2P trading, comprehensively. Most majority of the literature only solves smart grid trading in isolation. It is divorced from reality because many smart grids around the world depend on the generation of large-scale systems. Often, the internal generation of the grid (mostly renewable generation) is not enough to satisfy its demand. In these situations, it is necessary to buy electricity in the large and centralized markets through the DC. To attend to this issue, the proposed model addresses both systems by considering the dynamics of the smart grid into the large-scale system. It is the main difference between this integrated model and the rest of the models that face these problems. In those cases, models solve the smart grid in isolation, and its demand is subtracted from the total demand of the large-scale system and, then, both costs are added. To prove the effectiveness of the new proposal, the model solves the test case formed by the Armstrong smart grid fully connected with the Argentine largescale electric system. Results indicate that the cost of the integrated system is reduced at least 5\% in comparison with other results. Another key of this proposal is the fact that the CPU times are less than 2 sec. The low computational requirement allows obtaining, almost immediately, feasible solutions when any parameter of the grid changes.

\section{Funding}

This research did not receive any specific grant from funding agencies in the public, commercial, or not-for-profit sectors.

\section{References}

Alvarez, G. E. (2020). Integrated scheduling from a diversity of sources applied to the Argentine electric power and natural gas systems. Computers \& Chemical Engineering, 134, 106691. https://doi.org/10.1016/j.compchemeng.2019.106691

Ardani, K., Cook, J. J., Fu, R., \& Margolis, R. (2018). Cost-reduction Roadmap for Residential Solar Photovoltaics (PV), 2017-2030. National Renewable Energy Laboratory. https://prod-edxapp.edxcdn.org/assets/courseware/v1/507592ed43b3717c77aaf903ee14cc75/asset-

v1:SDGAcademyX+CA001+1T2019+type@asset+block/3.S_NREL_2018_.Costreduction_roadmap_for_residential_solar_photovoltaics_PV_2017-2030.p $\overline{\mathrm{d} f}$

Bahaj, A. S., Myers, L., \& James, P. A. B. (2007). Urban energy generation: Influence of micro-wind turbine output on electricity consumption in buildings. Energy and Buildings, 39(2), 154-165. https://doi.org/10.1016/j.enbuild.2006.06.001

Basnet, A., \& Zhong, J. (2020). Integrating gas energy storage system in a peer-to-peer community energy market for enhanced operation. International Journal of Electrical Power \& Energy Systems, $118,105789$. https://doi.org/10.1016/j.ijepes.2019.105789

Bell, K., \& Gill, S. (2018). Delivering a highly distributed electricity system: Technical, regulatory and policy challenges. Energy Policy, 113(October 2017), 765-777. https://doi.org/10.1016/j.enpol.2017.11.039

Biswas, B., \& Gupta, R. (2019). Analysis of barriers to implement blockchain in industry and service sectors. Computers \& Industrial Engineering, 136, 225-241. https://doi.org/10.1016/j.cie.2019.07.005

Bussieck, M., \& Meeraus, A. (2004). General algebraic modeling system (GAMS). Applied Optimization, 88, $137-158$. https://doi.org/10.1007/978-1-4613-0215-5_8

De Martini, P., Kristov, L., \& Schwartz, L. (2015). Distribution systems in a high distributed energy resources future.

Dileep, G. (2020). A survey on smart grid technologies and applications. Renewable Energy, 146, $2589-2625$. https://doi.org/10.1016/j.renene.2019.08.092

El-hawary, M. E. (2014). The Smart Grid-State-of-the-art and Future Trends. Electric Power Components and Systems, 42(3-4), 239-250. https://doi.org/10.1080/15325008.2013.868558

Gharavi, H., \& Ghafurian, R. (2011). Smart grid: The electric energy system of the future. Proceedings of the IEEE. https://doi.org/10.1109/JPROC.2011.2124210 
Guido, L. M. (2018). Technologies, communication and energy in Argentina: Smart Grid in the province of Santa Fe. Questión, 1(60), 104. https://doi.org/10.24215/16696581e104

Hasan, H., AlHadhrami, E., AlDhaheri, A., Salah, K., \& Jayaraman, R. (2019). Smart contract-based approach for efficient shipment management. Computers \& Industrial Engineering, 136, 149-159. https://doi.org/10.1016/j.cie.2019.07.022

Hayes, B. P., Thakur, S., \& Breslin, J. G. (2020). Co-simulation of electricity distribution networks and peer to peer energy trading platforms. International Journal of Electrical Power \& Energy Systems, $115,105419$. https://doi.org/10.1016/j.ijepes.2019.105419

Huang, Y.-F., Werner, S., Huang, J., Kashyap, N., \& Gupta, V. (2012). State Estimation in Electric Power Grids: Meeting New Challenges Presented by the Requirements of the Future Grid. IEEE Signal Processing Magazine, 29(5), 33-43. https://doi.org/10.1109/MSP.2012.2187037

Hug, G., Kar, S., \& Wu, C. (2015). Consensus + Innovations Approach for Distributed Multiagent Coordination in a Microgrid. IEEE Transactions on Smart Grid, 6(4), 1893-1903. https://doi.org/10.1109/TSG.2015.2409053

IBM ILOG CPLEX Optimizer. Version 12.3.0.0. Jul 2011. (20 C.E.).

IEA. (2019). World Energy Investment 2019.

Ipakchi, A., \& Albuyeh, F. (2009). Grid of the future. IEEE Power and Energy Magazine, 7(2), 52-62. https://doi.org/10.1109/MPE.2008.931384

Joas, F., Pahle, M., Flachsland, C., \& Joas, A. (2016). Which goals are driving the Energiewende? Making sense of the German Energy Transformation. Energy Policy, 95, 42-51. https://doi.org/10.1016/j.enpol.2016.04.003

Johnston, J. (2017). Peer-to-Peer Energy Matching: Transparency, Choice, and Locational Grid Pricing. In Innovation and Disruption at the Grid's Edge (pp. 319-330). Elsevier. https://doi.org/10.1016/B978-0-12-811758-3.00016-4

Kang, J., Yu, R., Huang, X., Maharjan, S., Zhang, Y., \& Hossain, E. (2017). Enabling Localized Peer-to-Peer Electricity Trading Among Plug-in Hybrid Electric Vehicles Using Consortium Blockchains. IEEE Transactions on Industrial Informatics, 13(6), 3154-3164. https://doi.org/10.1109/TII.2017.2709784

Khorasany, M., Mishra, Y., \& Ledwich, G. (2019). A Decentralised Bilateral Energy Trading System for Peer-to-Peer Electricity Markets. IEEE Transactions on Industrial Electronics, 0046(c), 1-1. https://doi.org/10.1109/tie.2019.2931229

Kristov, L. (2019). The Bottom-Up (R)Evolution of the Electric Power System: The Pathway to the Integrated-Decentralized System. IEEE Power and Energy Magazine, 17(2), 42-49. https://doi.org/10.1109/MPE.2018.2885204

Kusakana, K. (2019). Optimal Peer-to-Peer energy sharing between prosumers using hydrokinetic, diesel generator and pumped hydro storage. Journal of Energy Storage, 26, 101048. https://doi.org/10.1016/j.est.2019.101048

Li, Z., Bahramirad, S., Paaso, A., Yan, M., \& Shahidehpour, M. (2019). Blockchain for decentralized transactive energy management system in networked microgrids. Electricity Journal, 32(4), 58-72. https://doi.org/10.1016/j.tej.2019.03.008

Lima, R. M., \& Grossmann, I. E. (2011). Computational advances in solving mixed integer linear programming problems. Chemical Engineering Greetings to Prof. Sauro Pierucci on Occasion of His 65th Birthday, 151-160. http://repository.cmu.edu/cgi/viewcontent.cgi?article=1294\&context=cheme

Lin, J., Pipattanasomporn, M., \& Rahman, S. (2019). Comparative analysis of auction mechanisms and bidding strategies for P2P solar transactive energy markets. Applied Energy, 255, 113687. https://doi.org/10.1016/j.apenergy.2019.113687

Liu, N., Yu, X., Wang, C., Li, C., Ma, L., \& Lei, J. (2017). An Energy-Sharing Model with Price-Based Demand Response for Microgrids of Peer-to-Peer Prosumers. IEEE Transactions on Power Systems, 32(5), 3569-3583. https://doi.org/10.1109/TPWRS.2017.2649558

Liu, Y., Wu, L., \& Li, J. (2019). Peer-to-peer (P2P) electricity trading in distribution systems of the future. Electricity Journal, 32(4), 2-6. https://doi.org/10.1016/j.tej.2019.03.002

Long, C., Wu, J., Zhou, Y., \& Jenkins, N. (2018). Peer-to-peer energy sharing through a two-stage aggregated battery control in a community Microgrid. Applied Energy, 226(March), 261-276. https://doi.org/10.1016/j.apenergy.2018.05.097

Moret, F., \& Pinson, P. (2019). Energy Collectives: A Community and Fairness Based Approach to Future Electricity Markets. IEEE Transactions on Power Systems, 34(5), 3994-4004. https://doi.org/10.1109/TPWRS.2018.2808961

Nakayama, K., Moslemi, R., \& Sharma, R. (2019). Transactive Energy Management with Blockchain Smart Contracts for P2P Multi-Settlement Markets. 2019 IEEE Power \& Energy Society Innovative Smart Grid Technologies Conference (ISGT), 1-5. https://doi.org/10.1109/ISGT.2019.8791652

Park, C., \& Yong, T. (2017). Comparative review and discussion on P2P electricity trading. Energy Procedia, $128,3-9$. https://doi.org/10.1016/j.egypro.2017.09.003

Reka, S. S., \& Dragicevic, T. (2018). Future effectual role of energy delivery: A comprehensive review of Internet of Things and smart grid. Renewable and Sustainable Energy Reviews, 91, 90-108. https://doi.org/10.1016/j.rser.2018.03.089

Ribeiro, P., Polinder, H., \& Verkerk, M. (2012). Planning and Designing Smart Grids: Philosophical Considerations. IEEE Technology and Society Magazine, 31(3), 34-43. https://doi.org/10.1109/MTS.2012.2211771

Rodrigues, D. L., Ye, X., Xia, X., \& Zhu, B. (2020). Battery energy storage sizing optimisation for different ownership structures in a peer-to-peer energy sharing community. Applied Energy, $262,114498$. https://doi.org/10.1016/j.apenergy.2020.114498

Schröder, A., Kunz, F., Meiss, J., Mendelevitch, R. von, \& Hirschhausen, C. (2013). Current and prospective costs of electricity generation until 2050. http://hdl.handle.net/10419/80348\%0D

Slowik, P., Pavlenko, N., \& Lutsey, N. (2016). Assessment of next-generation electric vehicle technologies. White Paper. www. theicct. org/sites/default/files/publications/Next\%25 20Gen\%25 20EV\%25 20Tech_whitepaper_ICCT_31102016. pdf 
Sorin, E., Bobo, L., \& Pinson, P. (2019). Consensus-Based Approach to Peer-to-Peer Electricity Markets With Product Differentiation. IEEE Transactions on Power Systems, 34(2), 994-1004. https://doi.org/10.1109/TPWRS.2018.2872880

Talpone, J. I., Puleston, P. F., Cendoya, M. G. Battaiotto, P. E. (2016). Rol de las energías alternativas en la perspectiva de generación eléctrica en la República Argentina. II Congreso de Energías Sustentables, 7.

Tushar, W., Saha, T. K., Yuen, C., Azim, M. I., Morstyn, T., Poor, H. V., Niyato, D., \& Bean, R. (2020). A coalition formation game framework for peer-to-peer energy trading. Applied Energy, $261, \quad 114436$. https://doi.org/10.1016/j.apenergy.2019.114436

Tushar, W., Saha, T. K., Yuen, C., Morstyn, T., McCulloch, M. D., Poor, H. V., \& Wood, K. L. (2019). A motivational gametheoretic approach for peer-to-peer energy trading in the smart grid. Applied Energy, 243, 10-20. https://doi.org/10.1016/j.apenergy.2019.03.111

U.S. Department of Energy. (2017). Transforming the Nation's Electricity System: The Second Installment of the QER. In QUADRENNIAL ENERGY REVIEW: SECOND SINTALLMENT $\quad$ (p. https://www.energy.gov/sites/prod/files/2017/02/f34/Chapter I--Transforming the Nation\%27s Electricity System.pdf

Wandhare, R. G., \& Agarwal, V. (2014). Novel Stability Enhancing Control Strategy for Centralized PV-Grid Systems for Smart Grid Applications. IEEE Transactions on Smart Grid, 5(3), 1389-1396. https://doi.org/10.1109/TSG.2013.2279605

Yebiyo, M., Mercado, R. A., Gillich, A., Chaer, I., Day, A. R., \& Paurine, A. (2020). Novel economic modelling of a peerto-peer electricity market with the inclusion of distributed energy storage-The possible case of a more robust and better electricity grid. The Electricity Journal, 33(2), 106709. https://doi.org/10.1016/j.tej.2020.106709

Zhou, K., Yang, S., Chen, Z., \& Ding, S. (2014). Optimal load distribution model of microgrid in the smart grid environment. Renewable and Sustainable Energy Reviews, 35, 304-310. https://doi.org/10.1016/j.rser.2014.04.028

Zhou, S., Zou, F., Wu, Z., Gu, W., Hong, Q., \& Booth, C. (2020). A smart community energy management scheme considering user dominated demand side response and P2P trading. International Journal of Electrical Power \& Energy Systems, 114, 105378. https://doi.org/10.1016/j.ijepes.2019.105378

\section{Appendix}

Table A.1

PV generation of peers 11,13 , and 18 (MWh). All test cases

\begin{tabular}{ccccccccccccccccc}
\hline $\mathrm{P} / \mathrm{H}$ & 8 & 9 & 10 & 11 & 12 & 13 & 14 & 15 & 16 & 17 \\
\hline 11 & 0.002 & 0.014 & 0.023 & 0.030 & 0.035 & 0.037 & 0.037 & 0.038 & 0.037 & 0.033 & 0.028 & 0.014 & 0.002 \\
13 & 0.002 & 0.014 & 0.023 & 0.030 & 0.035 & 0.037 & 0.037 & 0.038 & 0.037 & 0.033 & 0.028 & 0.014 & 0.002 \\
18 & 0.013 & 0.076 & 0.125 & 0.159 & 0.186 & 0.195 & 0.195 & 0.200 & 0.197 & 0.178 & 0.149 & 0.072 & 0.013 \\
\hline
\end{tabular}

Table A.2

Wind generation of peer $14(\mathrm{MWh})$. All test cases

\begin{tabular}{|c|c|c|c|c|c|c|c|c|c|c|c|}
\hline 1 & 2 & 3 & 4 & 5 & 6 & 7 & 8 & 9 & 10 & 11 & 12 \\
\hline 0.090 & 0.085 & 0.101 & 0.090 & 0.079 & 0.070 & 0.099 & 0.076 & 0.099 & 0.099 & 0.064 & 0.090 \\
\hline 13 & 14 & 15 & 16 & 17 & 18 & 19 & 20 & 21 & 22 & 23 & 24 \\
\hline 0.087 & 0.055 & 0.098 & 0.079 & 0.098 & 0.059 & 0.098 & 0.064 & 0.099 & 0.965 & 0.949 & 0.099 \\
\hline
\end{tabular}

Table A.3

Hourly peer consumption (kWh). All test cases

\begin{tabular}{|c|c|c|c|c|c|c|c|c|c|c|c|c|c|c|c|c|c|c|c|}
\hline & 1 & 2 & 3 & 4 & 5 & 6 & 7 & 8 & 9 & 10 & 11 & 12 & 13 & 14 & 15 & 16 & 17 & 18 & 19 \\
\hline 1 & 76.5 & 84.6 & 90.4 & 85.5 & 99.0 & 92.2 & 91.8 & 91.3 & 78.8 & 2.3 & 0.2 & 92.2 & 0.2 & 0.5 & 106.6 & 90.6 & 113.6 & 4.2 & 97.3 \\
\hline 2 & 71.8 & 79.5 & 84.9 & 80.3 & 93.0 & 86.6 & 86.2 & 85.8 & 74.0 & 2.2 & 0.2 & 86.6 & 0.2 & 0.4 & 100.1 & 85.1 & 106.7 & 3.9 & 91.4 \\
\hline 3 & 71.4 & 78.9 & 84.4 & 79.8 & 92.4 & 86.1 & 85.7 & 85.2 & 73.5 & 2.2 & 0.2 & 86.1 & 0.2 & 0.4 & 99.5 & 84.6 & 106.0 & 3.9 & 90.8 \\
\hline 4 & 67.2 & 74.3 & 79.4 & 75.1 & 87.0 & 81.1 & 80.6 & 80.2 & 69.2 & 2.0 & 10.0 & 81.1 & 10.0 & 0.4 & 93.7 & 79.6 & 99.8 & 3.7 & 85.5 \\
\hline 5 & 62.6 & 69.2 & 73.9 & 70.0 & 81.0 & 75.5 & 75.1 & 74.7 & 64.5 & 1.9 & 10.0 & 75.5 & 10.0 & 0.4 & 87.2 & 74.1 & 92.9 & 3.4 & 79.6 \\
\hline 6 & 58.4 & 64.6 & 69.0 & 65.3 & 75.6 & 70.4 & 70.1 & 69.7 & 60.2 & 1.8 & 10.0 & 70.4 & 10.0 & 0.4 & 81.4 & 69.2 & 86.7 & 3.2 & 74.3 \\
\hline 7 & 57.9 & 64.1 & 68.5 & 64.8 & 75.0 & 69.9 & 69.5 & 69.2 & 59.7 & 1.8 & 10.0 & 69.9 & 10.0 & 0.4 & 80.8 & 68.6 & 86.0 & 3.2 & 73.7 \\
\hline 8 & 62.1 & 68.7 & 73.4 & 69.4 & 80.4 & 74.9 & 74.5 & 74.2 & 64.0 & 1.9 & 10.0 & 74.9 & 10.0 & 0.4 & 86.6 & 73.6 & 92.2 & 3.4 & 79.0 \\
\hline 9 & 65.8 & 72.8 & 77.8 & 73.6 & 85.2 & 79.4 & 79.0 & 78.6 & 67.8 & 2.0 & 10.0 & 79.4 & 10.0 & 0.4 & 91.7 & 78.0 & 97.7 & 3.6 & 83.8 \\
\hline 10 & 67.2 & 74.3 & 79.4 & 75.1 & 87.0 & 81.1 & 80.6 & 80.2 & 69.2 & 2.0 & 10.0 & 81.1 & 10.0 & 0.4 & 93.7 & 79.6 & 99.8 & 3.7 & 85.5 \\
\hline 11 & 69.5 & 76.9 & 82.2 & 77.7 & 90.0 & 83.8 & 83.4 & 83.0 & 71.6 & 2.1 & 0.2 & 83.8 & 0.2 & 0.4 & 96.9 & 82.4 & 103.2 & 3.8 & 88.5 \\
\hline 12 & 73.0 & 80.7 & 86.3 & 81.6 & 94.5 & 88.0 & 87.6 & 87.2 & 75.2 & 2.2 & 0.2 & 88.0 & 0.2 & 0.4 & 101.8 & 86.5 & 108.4 & 4.0 & 92.9 \\
\hline 13 & 76.5 & 84.6 & 90.4 & 85.5 & 99.0 & 92.2 & 91.8 & 91.3 & 78.8 & 2.3 & 0.2 & 92.2 & 0.2 & 0.5 & 106.6 & 90.6 & 113.6 & 4.2 & 97.3 \\
\hline 14 & 77.6 & 85.9 & 91.7 & 86.8 & 100.5 & 93.6 & 93.2 & 92.7 & 80.0 & 2.4 & 0.2 & 93.6 & 0.2 & 0.5 & 108.2 & 92.0 & 115.3 & 4.2 & 98.8 \\
\hline 15 & 81.1 & 89.7 & 95.9 & 90.7 & 105.0 & 97.8 & 97.3 & 96.8 & 83.6 & 2.5 & 0.2 & 97.8 & 0.2 & 0.5 & 113.1 & 96.1 & 120.4 & 4.4 & 103.2 \\
\hline 16 & 81.1 & 89.7 & 95.9 & 90.7 & 105.0 & 97.8 & 97.3 & 96.8 & 83.6 & 2.5 & 0.2 & 97.8 & 0.2 & 0.5 & 113.1 & 96.1 & 120.4 & 4.4 & 103.2 \\
\hline 17 & 80.6 & 89.2 & 95.3 & 90.2 & 104.4 & 97.3 & 96.8 & 96.3 & 83.1 & 2.4 & 0.2 & 97.3 & 0.2 & 0.5 & 112.4 & 95.6 & 119.7 & 4.4 & 102.6 \\
\hline 18 & 77.9 & 86.1 & 92.0 & 87.1 & 100.8 & 93.9 & 93.4 & 93.0 & 80.2 & 2.4 & 0.2 & 93.9 & 0.2 & 0.5 & 108.5 & 92.3 & 115.6 & 4.2 & 99.1 \\
\hline 19 & 76.5 & 84.6 & 90.4 & 85.5 & 99.0 & 92.2 & 91.8 & 91.3 & 78.8 & 2.3 & 0.2 & 92.2 & 0.2 & 0.5 & 106.6 & 90.6 & 113.6 & 4.2 & 97.3 \\
\hline 20 & 77.4 & 85.6 & 91.5 & 86.5 & 100.2 & 93.4 & 92.9 & 92.4 & 79.7 & 2.3 & 0.2 & 93.4 & 0.2 & 0.5 & 107.9 & 91.7 & 114.9 & 4.2 & 98.5 \\
\hline 21 & 78.1 & 86.4 & 92.3 & 87.3 & 101.1 & 94.2 & 93.7 & 93.2 & 80.5 & 2.4 & 0.2 & 94.2 & 0.2 & 0.5 & 108.9 & 92.5 & 116.0 & 4.3 & 99.4 \\
\hline 22 & 81.6 & 90.2 & 96.4 & 91.2 & 105.6 & 98.4 & 97.9 & 97.4 & 84.0 & 2.5 & 0.2 & 98.4 & 0.2 & 0.5 & 113.7 & 96.7 & 121.1 & 4.4 & 103.8 \\
\hline 23 & 82.5 & 91.3 & 97.5 & 92.3 & 106.8 & 99.5 & 99.0 & 98.5 & 85.0 & 2.5 & 0.3 & 99.5 & 0.3 & 0.5 & 115.0 & 97.8 & 122.5 & 4.5 & 105.0 \\
\hline 24 & 82.3 & 91.0 & 97.2 & 92.0 & 106.5 & 99.2 & 98.7 & 98.2 & 84.8 & 2.5 & 0.2 & 99.2 & 0.2 & 0.5 & 114.7 & 97.5 & 122.2 & 4.5 & 104.7 \\
\hline
\end{tabular}


Table A.4

Electricity purchase price between peers (USD/MWh). P2P and INT models

\begin{tabular}{cccccccccccccccccccccc}
\hline & 1 & 2 & 3 & 4 & 5 & 6 & 7 & 8 & 9 & 10 & 11 & 12 & 13 & 14 & 15 & 16 & 17 & 18 & 19 \\
\hline 1 & 000 & 152 & 153 & 163 & 165 & 168 & 230 & 233 & 218 & 219 & 221 & 223 & 225 & 219 & 221 & 223 & 220 & 222 & 250 \\
2 & 152 & 000 & 158 & 163 & 168 & 171 & 215 & 218 & 221 & 236 & 226 & 227 & 228 & 229 & 215 & 222 & 218 & 215 & 250 \\
3 & 153 & 158 & 000 & 159 & 161 & 163 & 218 & 221 & 236 & 228 & 218 & 233 & 218 & 232 & 223 & 224 & 219 & 231 & 250 \\
4 & 163 & 163 & 159 & 000 & 171 & 178 & 223 & 220 & 222 & 230 & 233 & 218 & 219 & 221 & 218 & 232 & 223 & 219 & 250 \\
5 & 165 & 168 & 161 & 171 & 000 & 174 & 219 & 221 & 223 & 225 & 233 & 218 & 232 & 223 & 224 & 219 & 231 & 215 & 250 \\
6 & 168 & 171 & 163 & 178 & 174 & 000 & 218 & 219 & 221 & 223 & 227 & 228 & 229 & 223 & 224 & 219 & 219 & 219 & 250 \\
7 & 230 & 215 & 218 & 223 & 219 & 218 & 000 & 169 & 188 & 218 & 232 & 223 & 224 & 233 & 218 & 232 & 223 & 228 & 250 \\
\hline 8 & 233 & 218 & 221 & 220 & 221 & 219 & 169 & 000 & 196 & 229 & 215 & 222 & 233 & 218 & 223 & 224 & 219 & 226 & 250 \\
9 & 218 & 221 & 236 & 222 & 223 & 221 & 188 & 196 & 000 & 218 & 219 & 221 & 223 & 225 & 223 & 224 & 233 & 219 & 250 \\
10 & 219 & 236 & 228 & 230 & 225 & 223 & 218 & 229 & 218 & 000 & 165 & 176 & 196 & 183 & 181 & 184 & 163 & 218 & 250 \\
11 & 221 & 226 & 218 & 233 & 233 & 227 & 232 & 215 & 219 & 165 & 000 & 176 & 196 & 183 & 181 & 184 & 163 & 219 & 250 \\
12 & 223 & 227 & 233 & 218 & 218 & 228 & 223 & 222 & 221 & 176 & 176 & 000 & 196 & 183 & 181 & 184 & 163 & 223 & 250 \\
13 & 225 & 228 & 218 & 219 & 232 & 229 & 224 & 233 & 223 & 196 & 196 & 196 & 000 & 183 & 181 & 184 & 163 & 226 & 250 \\
14 & 219 & 229 & 232 & 221 & 223 & 223 & 233 & 218 & 225 & 183 & 183 & 183 & 183 & 000 & 181 & 184 & 163 & 218 & 250 \\
15 & 221 & 215 & 223 & 218 & 224 & 224 & 218 & 223 & 223 & 181 & 181 & 181 & 181 & 181 & 000 & 184 & 163 & 233 & 250 \\
16 & 223 & 222 & 224 & 232 & 219 & 219 & 232 & 224 & 224 & 184 & 184 & 184 & 184 & 184 & 184 & 000 & 163 & 219 & 250 \\
17 & 220 & 218 & 219 & 223 & 231 & 219 & 223 & 219 & 233 & 163 & 163 & 163 & 163 & 163 & 163 & 163 & 000 & 223 & 250 \\
18 & 222 & 215 & 231 & 219 & 215 & 219 & 228 & 226 & 219 & 218 & 219 & 223 & 226 & 218 & 233 & 219 & 223 & 000 & 150 \\
19 & 250 & 250 & 250 & 250 & 250 & 250 & 250 & 250 & 250 & 250 & 250 & 250 & 250 & 250 & 250 & 250 & 250 & 150 & 000 \\
\hline
\end{tabular}

Table A.5

Electricity selling price between peers (USD/MWh). P2P Model and INT models

\begin{tabular}{|c|c|c|c|c|c|c|c|c|c|c|}
\hline & 1 & 2 & 3 & 4 & 5 & 6 & 7 & 8 & 9 & 10 \\
\hline 1 & 000.00 & 182.40 & 183.60 & 195.60 & 198.00 & 201.60 & 172.50 & 174.75 & 163.50 & 164.25 \\
\hline 2 & 182.40 & 000.00 & 189.60 & 195.60 & 201.60 & 205.20 & 161.25 & 163.50 & 165.75 & 177.00 \\
\hline 3 & 183.60 & 189.60 & 000.00 & 190.80 & 193.20 & 195.60 & 163.50 & 165.75 & 177.00 & 171.00 \\
\hline 4 & 195.60 & 195.60 & 190.80 & 000.00 & 205.20 & 213.60 & 167.25 & 165.00 & 166.50 & 172.50 \\
\hline 5 & 198.00 & 201.60 & 193.20 & 205.20 & 000.00 & 208.80 & 164.25 & 165.75 & 167.25 & 168.75 \\
\hline 6 & 201.60 & 205.20 & 195.60 & 213.60 & 208.80 & 000.00 & 163.50 & 164.25 & 165.75 & 167.25 \\
\hline 7 & 172.50 & 161.25 & 163.50 & 167.25 & 164.25 & 163.50 & 000.00 & 202.80 & 225.60 & 163.50 \\
\hline 8 & 174.75 & 163.50 & 165.75 & 165.00 & 165.75 & 164.25 & 202.80 & 000.00 & 235.20 & 171.75 \\
\hline 9 & 163.50 & 165.75 & 177.00 & 166.50 & 167.25 & 165.75 & 225.60 & 235.20 & 000.00 & 163.50 \\
\hline 10 & 164.25 & 177.00 & 171.00 & 172.50 & 168.75 & 167.25 & 163.50 & 171.75 & 163.50 & 000.00 \\
\hline 11 & 165.75 & 169.50 & 163.50 & 174.75 & 174.75 & 170.25 & 174.00 & 161.25 & 164.25 & 198.00 \\
\hline 12 & 167.25 & 170.25 & 174.75 & 163.50 & 163.50 & 171.00 & 167.25 & 166.50 & 165.75 & 211.20 \\
\hline 13 & 168.75 & 171.00 & 163.50 & 164.25 & 174.00 & 171.75 & 168.00 & 174.75 & 167.25 & 235.20 \\
\hline 14 & 164.25 & 171.75 & 174.00 & 165.75 & 167.25 & 167.25 & 174.75 & 163.50 & 168.75 & 219.60 \\
\hline 15 & 165.75 & 161.25 & 167.25 & 163.50 & 168.00 & 168.00 & 163.50 & 167.25 & 167.25 & 217.20 \\
\hline 16 & 167.25 & 166.50 & 168.00 & 174.00 & 164.25 & 164.25 & 174.00 & 168.00 & 168.00 & 220.80 \\
\hline 17 & 165.00 & 163.50 & 164.25 & 167.25 & 173.25 & 164.25 & 167.25 & 164.25 & 174.75 & 195.60 \\
\hline 18 & 166.50 & 161.25 & 173.25 & 164.25 & 161.25 & 164.25 & 171.00 & 169.50 & 164.25 & 261.60 \\
\hline \multirow[t]{2}{*}{19} & 150.00 & 150.00 & 150.00 & 150.00 & 150.00 & 150.00 & 150.00 & 150.00 & 150.00 & 150.00 \\
\hline & 11 & 12 & 13 & 14 & 15 & 16 & 17 & 18 & 19 & \\
\hline 1 & 165.75 & 167.25 & 168.75 & 164.25 & 165.75 & 167.25 & 165.00 & 166.50 & 150.00 & \\
\hline 2 & 169.50 & 170.25 & 171.00 & 171.75 & 161.25 & 166.50 & 163.50 & 161.25 & 150.00 & \\
\hline 3 & 163.50 & 174.75 & 163.50 & 174.00 & 167.25 & 168.00 & 164.25 & 173.25 & 150.00 & \\
\hline 4 & 174.75 & 163.50 & 164.25 & 165.75 & 163.50 & 174.00 & 167.25 & 164.25 & 150.00 & \\
\hline 5 & 174.75 & 163.50 & 174.00 & 167.25 & 168.00 & 164.25 & 173.25 & 161.25 & 150.00 & \\
\hline 6 & 170.25 & 171.00 & 171.75 & 167.25 & 168.00 & 164.25 & 164.25 & 164.25 & 150.00 & \\
\hline 7 & 174.00 & 167.25 & 168.00 & 174.75 & 163.50 & 174.00 & 167.25 & 171.00 & 150.00 & \\
\hline 8 & 161.25 & 166.50 & 174.75 & 163.50 & 167.25 & 168.00 & 164.25 & 169.50 & 150.00 & \\
\hline 9 & 164.25 & 165.75 & 167.25 & 168.75 & 167.25 & 168.00 & 174.75 & 164.25 & 150.00 & \\
\hline 10 & 198.00 & 211.20 & 235.20 & 219.60 & 217.20 & 220.80 & 195.60 & 163.50 & 150.00 & \\
\hline 11 & 000.00 & 211.20 & 235.20 & 219.60 & 217.20 & 220.80 & 195.60 & 164.25 & 150.00 & \\
\hline 12 & 211.20 & 000.00 & 235.20 & 219.60 & 217.20 & 220.80 & 195.60 & 167.25 & 150.00 & \\
\hline 13 & 235.20 & 235.20 & 000.00 & 219.60 & 217.20 & 220.80 & 195.60 & 169.50 & 150.00 & \\
\hline 14 & 219.60 & 219.60 & 219.60 & 000.00 & 217.20 & 220.80 & 195.60 & 163.50 & 150.00 & \\
\hline 15 & 217.20 & 217.20 & 217.20 & 217.20 & 000.00 & 220.80 & 195.60 & 174.75 & 150.00 & \\
\hline 16 & 220.80 & 220.80 & 220.80 & 220.80 & 220.80 & 000.00 & 195.60 & 164.25 & 150.00 & \\
\hline 17 & 195.60 & 195.60 & 195.60 & 195.60 & 195.60 & 195.60 & 000.00 & 167.25 & 150.00 & \\
\hline 18 & 262.80 & 267.60 & 271.20 & 261.60 & 279.60 & 262.80 & 267.60 & 000.00 & 170.00 & \\
\hline 19 & 150.00 & 150.00 & 150.00 & 150.00 & 150.00 & 150.00 & 150.00 & 170.00 & 000.00 & \\
\hline
\end{tabular}


Table A.6

Cost for using transmission lines (USD/MW). P2P Model and INT models

\begin{tabular}{lllllllllllllllllllll}
\hline & 1 & 2 & 3 & 4 & 5 & 6 & 7 & 8 & 9 & 10 & 11 & 12 & 13 & 14 & 15 & 16 & 17 & 18 & 19 \\
\hline 1 & 00 & 22 & 22 & 23 & 24 & 24 & 33 & 33 & 31 & 31 & 32 & 32 & 32 & 31 & 32 & 32 & 31 & 32 & 17 \\
2 & 22 & 00 & 23 & 23 & 24 & 24 & 31 & 31 & 32 & 34 & 32 & 32 & 33 & 33 & 31 & 32 & 31 & 31 & 17 \\
3 & 22 & 23 & 00 & 23 & 23 & 23 & 31 & 32 & 34 & 33 & 31 & 33 & 31 & 33 & 32 & 32 & 31 & 33 & 17 \\
\hline & 23 & 23 & 23 & 00 & 24 & 25 & 32 & 31 & 32 & 33 & 33 & 31 & 31 & 32 & 31 & 33 & 32 & 31 & 17 \\
\hline 5 & 24 & 24 & 23 & 24 & 00 & 25 & 31 & 32 & 32 & 32 & 33 & 31 & 33 & 32 & 32 & 31 & 33 & 31 & 17 \\
6 & 24 & 24 & 23 & 25 & 25 & 00 & 31 & 31 & 32 & 32 & 32 & 33 & 33 & 32 & 32 & 31 & 31 & 31 & 17 \\
7 & 33 & 31 & 31 & 32 & 31 & 31 & 00 & 24 & 27 & 31 & 33 & 32 & 32 & 33 & 31 & 33 & 32 & 33 & 17 \\
8 & 33 & 31 & 32 & 31 & 32 & 31 & 24 & 00 & 28 & 33 & 31 & 32 & 33 & 31 & 32 & 32 & 31 & 32 & 17 \\
9 & 31 & 32 & 34 & 32 & 32 & 32 & 27 & 28 & 00 & 31 & 31 & 32 & 32 & 32 & 32 & 32 & 33 & 31 & 17 \\
10 & 31 & 34 & 33 & 33 & 32 & 32 & 31 & 33 & 31 & 00 & 24 & 25 & 28 & 26 & 26 & 26 & 23 & 31 & 17 \\
11 & 32 & 32 & 31 & 33 & 33 & 32 & 33 & 31 & 31 & 24 & 00 & 25 & 28 & 26 & 26 & 26 & 23 & 31 & 17 \\
12 & 32 & 32 & 33 & 31 & 31 & 33 & 32 & 32 & 32 & 25 & 25 & 00 & 28 & 26 & 26 & 26 & 23 & 32 & 17 \\
13 & 32 & 33 & 31 & 31 & 33 & 33 & 32 & 33 & 32 & 28 & 28 & 28 & 00 & 26 & 26 & 26 & 23 & 32 & 17 \\
14 & 31 & 33 & 33 & 32 & 32 & 32 & 33 & 31 & 32 & 26 & 26 & 26 & 26 & 00 & 26 & 26 & 23 & 31 & 17 \\
15 & 32 & 31 & 32 & 31 & 32 & 32 & 31 & 32 & 32 & 26 & 26 & 26 & 26 & 26 & 00 & 26 & 23 & 33 & 17 \\
16 & 32 & 32 & 32 & 33 & 31 & 31 & 33 & 32 & 32 & 26 & 26 & 26 & 26 & 26 & 26 & 00 & 23 & 31 & 17 \\
17 & 31 & 31 & 31 & 32 & 33 & 31 & 32 & 31 & 33 & 23 & 23 & 23 & 23 & 23 & 23 & 23 & 00 & 32 & 17 \\
18 & 32 & 31 & 33 & 31 & 31 & 31 & 33 & 32 & 31 & 31 & 31 & 32 & 32 & 31 & 33 & 31 & 32 & 00 & 17 \\
19 & 17 & 17 & 17 & 17 & 17 & 17 & 17 & 17 & 17 & 17 & 17 & 17 & 17 & 17 & 17 & 17 & 17 & 17 & 00 \\
\hline
\end{tabular}

Table A.7

Buying costs between CMs and peers (USD/MWh). CM and INT models

\begin{tabular}{|c|c|c|c|c|c|c|c|c|c|c|c|c|c|c|c|c|c|c|c|}
\hline \multirow[b]{2}{*}{$\mathrm{CM}$} & \multicolumn{19}{|c|}{ Peers } \\
\hline & 1 & 2 & 3 & 4 & 5 & 6 & 7 & 8 & 9 & 10 & 11 & 12 & 13 & 14 & 15 & 16 & 17 & 18 & 19 \\
\hline 1 & 152 & 153 & 163 & 165 & 168 & 163 & 600 & 600 & 600 & 600 & 600 & 600 & 600 & 600 & 600 & 600 & 600 & 600 & 600 \\
\hline 2 & 600 & 600 & 600 & 600 & 600 & 600 & 163 & 168 & 171 & 600 & 600 & 600 & 600 & 600 & 600 & 600 & 600 & 600 & 600 \\
\hline 3 & 600 & 600 & 600 & 600 & 600 & 600 & 600 & 600 & 600 & 165 & 168 & 163 & 165 & 168 & 163 & 165 & 168 & 600 & 600 \\
\hline 4 & 600 & 600 & 600 & 600 & 600 & 600 & 600 & 600 & 600 & 600 & 600 & 600 & 600 & 600 & 600 & 600 & 600 & 162 & 600 \\
\hline
\end{tabular}

Table A.8

Selling prices between CMs and peers (USD/MWh). CM and INT models

\begin{tabular}{|c|c|c|c|c|c|c|c|c|c|c|c|c|c|c|c|c|c|c|c|}
\hline \multirow[b]{2}{*}{$\mathrm{CM}$} & \multicolumn{19}{|c|}{ Peers } \\
\hline & 1 & 2 & 3 & 4 & 5 & 6 & 7 & 8 & 9 & 10 & 11 & 12 & 13 & 14 & 15 & 16 & 17 & 18 & 19 \\
\hline 1 & 175 & 176 & 179 & 181 & 165 & 166 & 001 & 001 & 001 & 001 & 001 & 001 & 001 & 001 & 001 & 001 & 001 & 001 & 001 \\
\hline 2 & 001 & 001 & 001 & 001 & 001 & 001 & 177 & 178 & 179 & 001 & 001 & 001 & 001 & 001 & 001 & 001 & 001 & 001 & 001 \\
\hline 3 & 001 & 001 & 001 & 001 & 001 & 001 & 001 & 001 & 001 & 188 & 187 & 183 & 179 & 186 & 188 & 191 & 196 & 001 & 001 \\
\hline 4 & 001 & 001 & 001 & 001 & 001 & 001 & 001 & 001 & 001 & 001 & 001 & 001 & 001 & 001 & 001 & 001 & 001 & 188 & 001 \\
\hline
\end{tabular}

Table A.9

Cost for using transmission lines (USD/MW). CM model and INT models

\begin{tabular}{|c|c|c|c|c|c|c|c|c|c|c|c|c|c|c|c|c|c|c|c|}
\hline \multirow[b]{2}{*}{$\mathrm{CM}$} & \multicolumn{19}{|c|}{ Peers } \\
\hline & 1 & 2 & 3 & 4 & 5 & 6 & 7 & 8 & 9 & 10 & 11 & 12 & 13 & 14 & 15 & 16 & 17 & 18 & 19 \\
\hline 1 & 017 & 018 & 019 & 018 & 017 & 015 & 300 & 300 & 300 & 300 & 300 & 300 & 300 & 300 & 300 & 300 & 300 & 300 & 300 \\
\hline 2 & 300 & 300 & 300 & 300 & 300 & 300 & 300 & 015 & 016 & 300 & 300 & 300 & 300 & 300 & 300 & 300 & 300 & 300 & 300 \\
\hline 3 & 300 & 300 & 300 & 300 & 300 & 300 & 300 & 300 & 300 & 018 & 021 & 022 & 019 & 023 & 015 & 018 & 019 & 300 & 300 \\
\hline 4 & 300 & 300 & 300 & 300 & 300 & 300 & 300 & 300 & 300 & 300 & 300 & 300 & 300 & 300 & 300 & 300 & 300 & 021 & 300 \\
\hline
\end{tabular}

Table A.10

Trading costs between CMs (USD/MW). CM model and INT models

\begin{tabular}{ccccc}
\hline CM & 1 & 2 & 3 & 3 \\
\hline 1 & 0 & 2.1 & 2.5 & 3.3 \\
2 & 4.5 & 0 & 3.5 & 0 \\
3 & 2.5 & 3.5 & 2.1 & 2.8 \\
4 & 3.3 & 3.1 & 0 & 2.8 \\
\hline
\end{tabular}

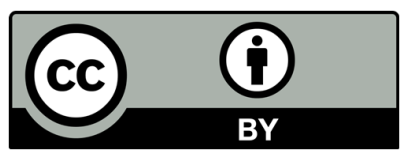

(C) 2022 by the authors; licensee Growing Science, Canada. This is an open access article distributed under the terms and conditions of the Creative Commons Attribution (CCBY) license (http://creativecommons.org/licenses/by/4.0/). 